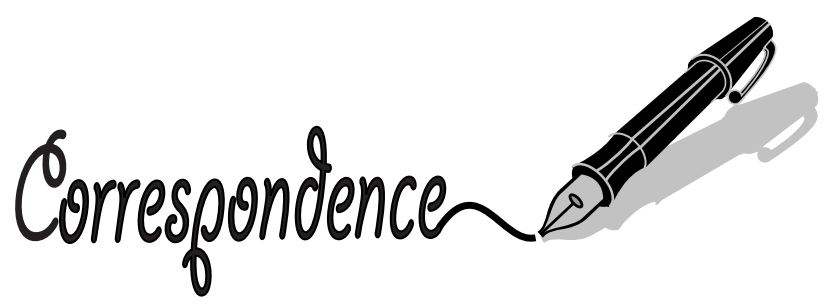

INSTRUCTIONS FOR LETTERS TO THE EDITOR

Editorial comment in the form of a Letter to the Editor is invited. The length of a letter should not exceed 800 words, with a maximum of 10 references and no more than 2 figures or tables; and no subdivision for an abstract, methods, or results. Letters should have no more than 4 authors. Financial associations or other possible conflicts of interest should be disclosed.

Letters should be submitted via our online submission system, available at the Manuscript Central website: http://mc.manuscriptcentral.com/jrheum For additional information, contact the Managing Editor, The Journal of Rheumatology, E-mail: jrheum@jrheum.com

\section{In Defense of Research into the Crystal Induced Arthropathies}

\section{To the Editor:}

We were most interested to read Prof. Pritzker's assessment of the state of research into the crystal induced arthropathies ${ }^{1}$. We wish to assure Prof. Pritzker and the wider rheumatology community that, rather than being a "dwindling endangered species whose interests are seen to be peripheral to those of most rheumatologists," those researchers involved in studying the crystal induced arthropathies are enthusiastic, energetic, and productive.
In recent years, work in this field has led to critical advances in our understanding of the basic science and epidemiology of crystal induced arthropathies $^{2-6}$. Further, the prospect of new agents to treat these diseases is cause for great enthusiasm. For management of acute crystal induced arthropathies, components of the inflammasome, and particularly interleukin 1, provide new therapeutic targets. The development of novel uratelowering therapies, such as febuxostat and PEG-uricase for treatment of chronic gout, should also have a major impact on longterm management of this prevalent disease, in preventing acute gout attacks and the consequences of chronic gout such as disfiguring tophi, joint damage, and disability ${ }^{7,8}$.

As a reflection of the interest in gout within the rheumatology community, gout sessions have been included in the scientific programs of the 2 last EULAR annual meetings, the 2 last ACR annual meetings, and as Special Interest Groups (SIG) or Workshops in the last 3 OMERACT meetings. EULAR has recently supported a Task Force on Gout, resulting in the publication of Evidence Based Recommendations for Diagnosis and Management ${ }^{9,10}$, and the ACR and EULAR have funded an international project for validation of acute gout flares. The number of presentations at ACR and EULAR meetings is 10 times that of a decade ago, and the number of original papers on gout in high impact international journals now exceeds that of reviews, a situation inverse to that observed a decade ago. In addition, as the reader may observe, the group of investigators devoted to gout does not have the appearance of an endangered species (Figure 1).

It is for these reasons that we do not share Prof. Pritzker's pessimistic view regarding the state of research into the crystal induced arthropathies. The number of investigators may be small, but recent progress has been significant and is likely to translate into important new treatments for patients with these diseases.

NICOLA DALBETH, MD, FRACP, Department of Medicine, University of Auckland, 85 Park Rd, Grafton, Auckland, New Zealand;

E-mail: n.dalbeth@auckland.ac.nz; FERNANDO PEREZ-RUIZ, MD, PhD, Rheumatology Division, Hospital de Cruces, Spain; N. LAWRENCE EDWARDS, MD, Department of Medicine, University of Florida, Gainesville, Florida; NAOMI SCHLESINGER, MD, Department of Medicine, UMDNJ-Robert Wood Johnson Medical School, New Brunswick, NJ, USA.

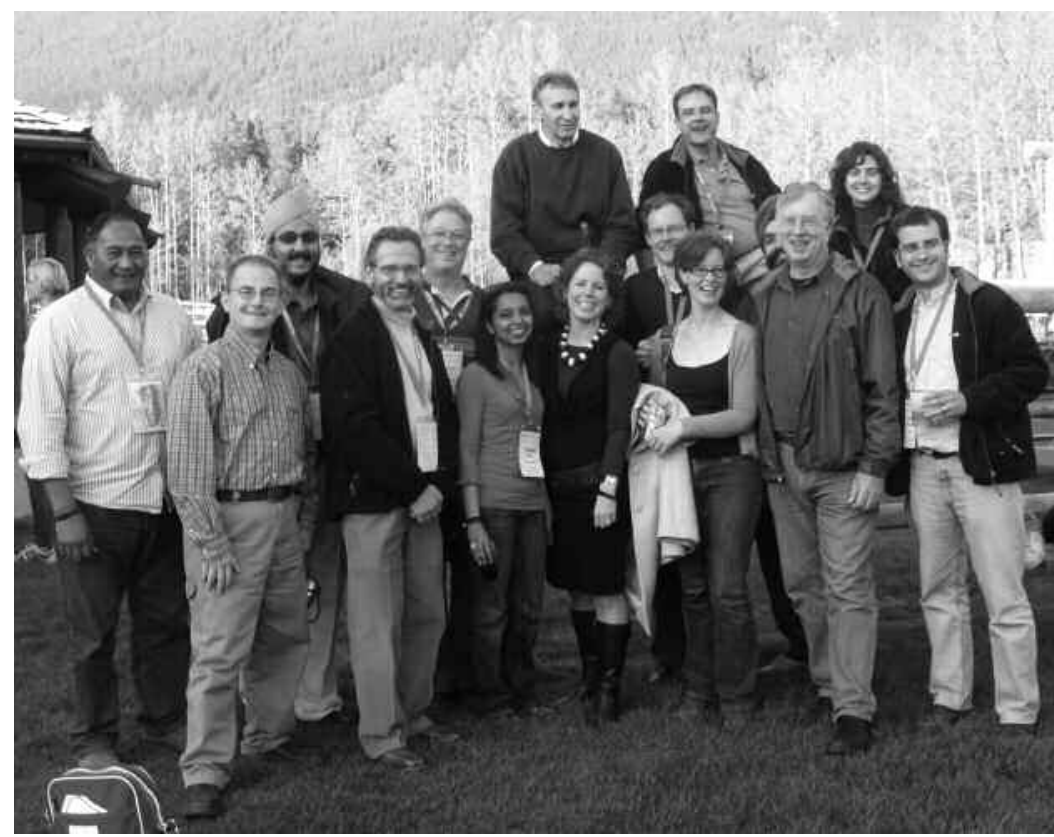

Figure 1. Some of the participants (patients and physicians) in the Gout Working Group at the OMERACT 9 Meeting, May 2008. Observe that they look far from being extinguished. 


\section{REFERENCES}

1. Pritzker KPH. Crystal Deposition in Joints: Prevalence and Relevance for Arthritis. J Rheumatol 2008;35:958-9.

2. Choi HK, Atkinson K, Karlson EW, Willett W, Curhan G. Purine-rich foods, dairy and protein intake, and the risk of gout in men. N Engl J Med 2004;350:1093-103.

3. Doring A, Gieger C, Mehta D, et al. SLC2A9 influences uric acid concentrations with pronounced sex-specific effects. Nat Genet 2008:40:430-6.

4. Enomoto A, Kimura H, Chairoungdua A, et al. Molecular identification of a renal urate anion exchanger that regulates blood urate levels. Nature 2002;417:447-52.

5. Martinon F, Petrilli V, Mayor A, Tardivel A, Tschopp J. Gout-associated uric acid crystals activate the NALP3 inflammasome. Nature 2006;440:237-41.

6. Shi Y, Evans JE, Rock KL. Molecular identification of a danger signal that alerts the immune system to dying cells. Nature 2003;425:516-21.

7. Becker MA, Schumacher HR, Jr., Wortmann RL, et al. Febuxostat compared with allopurinol in patients with hyperuricemia and gout. N Engl J Med 2005;353:2450-61.

8. Sundy JS, Ganson NJ, Kelly SJ, et al. Pharmacokinetics and pharmacodynamics of intravenous PEGylated recombinant mammalian urate oxidase in patients with refractory gout. Arthritis Rheum 2007;56:1021-8.

9. Zhang W, Doherty M, Bardin T, et al. EULAR evidence based recommendations for gout. Part II: Management. Report of a task force of the EULAR Standing Committee for International Clinical Studies Including Therapeutics (ESCISIT). Ann Rheum Dis 2006;65:1312-24.

10. Zhang W, Doherty M, Pascual E, et al. EULAR evidence based recommendations for gout. Part I: Diagnosis. Report of a task force of the Standing Committee for International Clinical Studies Including Therapeutics (ESCISIT). Ann Rheum Dis 2006;65:1301-11.

J Rheumatol 2008; 35:11; doi:10.3899/jrheum.080599

\section{Dr. Pritzker replies}

\section{To the Editor:}

It is delightful to note such a spirited and positive response by Dr. Dalbeth and colleagues to my deliberately provocative commentary. It is even more wonderful to see the representative list of high quality papers and the youthful appearance of the "regenerated" gout investigator species. Can we say the same for the calcium pyrophosphate crystal arthropathy research community?

Far from being pessimistic, my commentary was a rallying cry for more young rheumatologists to focus their professional clinical, research, and teaching interests on these very prevalent arthritic diseases. It is clear that the crystal arthritis patient population is abundant and that the research questions are both important and approachable. As well, from their letter it can be seen that the crystal arthropathy research community, small as it is, is enthusiastic and productive. What is needed now is expansion of the investigator community so that crystal-associated arthritic diseases can receive research attention proportional to their prevalence and their impact on patients.

KENNETH P.H. PRITZKER, MD, FRCPC, Pathology and Laboratory Medicine, Mount Sinai Hospital, 600 University Avenue, Toronto, Ontario M5G 1X5, Canada. E-mail: kpritzker@mtsinai.on.ca

\section{REFERENCE}

1. Pritzker KPH. Crystal deposition in joints: prevalence and relevance for arthritis. J Rheumatol 2008;35:958-9.

J Rheumatol 2008;35:11; doi:10.3899/jrheum.080690

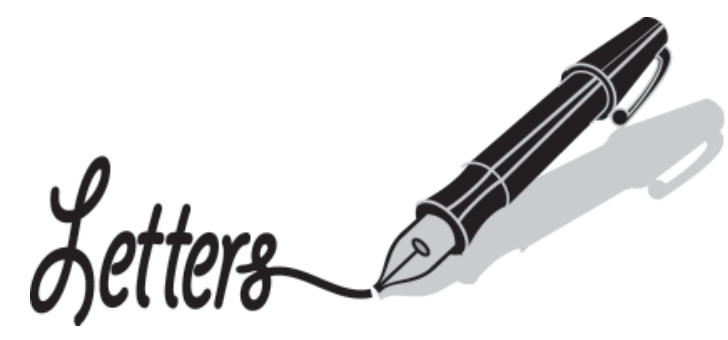

Etanercept-associated Pulmonary Granulomatous
Inflammation in Patients with Rheumatoid Arthritis

To the Editor:

We describe 4 patients with rheumatoid arthritis (RA) who developed noninfectious pulmonary granulomatous disease while treated with etanercept (Table 1). All patients improved with withdrawal of etanercept and addition of prednisone, without use of antibiotic, antifungal, or antimycobacterial medications. They were subsequently treated with adalimumab with no recurrence of pulmonary toxicity.

Patient 1. After an inadequate response to leflunomide, a 60-year-old man with 1 year of seropositive RA started etanercept, with subsequent improvement. He then experienced progressive malaise and a 40-lb weight loss. Chest radiograph and computed tomography (CT) scan revealed multiple pulmonary nodules bilaterally. Open-lung biopsy demonstrated large granulomas with palisading histiocytes and a necrotizing central zone. Tissue stains for acid-fast bacillus and fungi, routine cultures, and microscopic examination of stained specimens were negative. Polymerase chain reaction for mycobacterial infection, tests for fungal organisms, antineutrophil cytoplasmic antibodies, and antinuclear antibodies were all negative. Etanercept was discontinued and prednisone $10 \mathrm{mg}$ daily was added. Serial chest CT scans showed regression of the pulmonary nodules. One year later adalimumab was added because of progression of joint symptoms. He has tolerated adalimumab well for 4 years, and followup chest CT showed further regression of the pulmonary nodules.

Patient 2. A 60-year-old woman with erosive polyarticular, rheumatoid factor (RF)-positive RA since 1982 started methotrexate (MTX) in 1994, with addition of etanercept in 1999. In January 2001 she developed left chestwall herpes zoster and exertional dyspnea. High resolution CT (HRCT) demonstrated pleural effusions, interstitial lung disease, and scattered centrilobular nodules. Transbronchial biopsy revealed numerous confluent non-necrotic granulomas within the bronchial wall. Special stains for acidfast bacilli (AFB) and fungi were negative. She received prednisone 30 $\mathrm{mg}$ /day, reduced to $10 \mathrm{mg}$ daily over several months. MTX was withheld and etanercept was continued. Followup HRCT showed improvement. In September 2003 she complained of dyspnea and symptoms of an upper respiratory infection, and was treated for sinusitis with amoxicillin/clavulanate. Etanercept was stopped. Chest radiograph showed multiple reticular-nodular and ground-glass opacities throughout the lungs, more pronounced in the lower lung fields, and worse than in 2002. HRCT showed bilateral ground-glass opacity with basilar predominance, innumerable tiny nodules in the upper and mid-lungs, and thickened bands of fibrosis in both lung bases (Figure 1A). Transbronchial biopsy showed non-necrotic granulomatous inflammation (Figure 1B). Special stains for fungi and AFB were negative. Mycobacterium chelonae grown from AFB culture after 1 month was judged to be a contaminant. She started prednisone $30 \mathrm{mg}$ daily for 2 weeks with a slow taper. Followup HRCT showed complete resolution of micronodules and improvement of bilateral ground-glass opacity, with minimal fibrosis. Because of persistent symptoms of RA, adalimumab was added in August 2005, without worsening of pulmonary symptoms or pulmonary function tests. Chest radiograph 3 months later showed no pulmonary nodules.

Patient 3. A 66-year-old woman with erosive polyarticular RA since 1989 
Table 1. Patient characteristics.

\begin{tabular}{|c|c|c|c|c|c|c|c|c|c|c|c|c|}
\hline Case & $\begin{array}{l}\text { Age/ } \\
\text { Sex }\end{array}$ & $\begin{array}{l}\text { Disease } \\
\text { Duration }\end{array}$ & $\begin{array}{c}\text { RA } \\
\text { Features }\end{array}$ & $\begin{array}{l}\text { Etanercept } \\
\text { Duration }\end{array}$ & $\begin{array}{l}\text { Concurrent } \\
\text { DMARD }\end{array}$ & Smoking & Symptoms & $\begin{array}{l}\text { Previous } \\
\text { Chest X-ray }\end{array}$ & $\begin{array}{l}\text { Initital Chest } \\
\text { X-ray/HRCT }\end{array}$ & $\begin{array}{l}\text { Lung Biopsy } \\
\text { (all culture- } \\
\text { negative) }\end{array}$ & $\begin{array}{l}\text { Post-intervention } \\
\text { CT/Chest X-ray }\end{array}$ & Outcome \\
\hline 3 & $65 \mathrm{~F}$ & $18 \mathrm{yrs}$ & $\begin{array}{c}\text { Erosive, } \\
\text { polyarticular } \\
\text { RF+ }\end{array}$ & $4 \mathrm{yrs}$ & $\begin{array}{c}\text { Lef (past } \\
\text { use MTX, } \\
\text { HCQ, Aza) }\end{array}$ & $\begin{array}{l}20 \text { yrs; quit } \\
20 \text { yrs ago }\end{array}$ & $\begin{array}{l}\text { Dry cough, } \\
\text { malaise, } \\
\text { 30-lb wt loss }\end{array}$ & Normal & $\begin{array}{c}\text { Bilateral pulmonary } \\
\text { nodules, mediastinal } \\
\text { adenopathy }\end{array}$ & $\begin{array}{l}\text { Multiple } \\
\text { epithelioid } \\
\text { granulomas }\end{array}$ & $\begin{array}{l}\text { Improvement in } \\
\text { nodularity and } \\
\text { ground-glass } \\
\text { opacity }\end{array}$ & $\begin{array}{c}\text { Stable on } \\
\text { adalimumab }\end{array}$ \\
\hline
\end{tabular}

HRCT: high resolution computed tomography; DMARD: disease modifying antirheumatic drugs; MTX: methotrexate; SSZ: sulfasalazine; HCQ: hydroxychloroquine; Aza: azathioprine; Lef: leflunomide; CCP: cyclic citrullinated peptide; RF: rheumatoid factor; NA: not available.

started etanercept in 1999, with an excellent response. In August 2003, while receiving etanercept and leflunomide, she experienced insidious onset of dry cough, malaise, exertional dyspnea, and gastrointestinal (GI) distress. Leflunomide was discontinued and the GI symptoms resolved, but she remained ill. She had no fever, but her weight decreased by $30 \mathrm{lb}$ over 3 months. Etanercept was then stopped. Chest radiograph showed diffusely hazy lung fields and thickening of fissures with normal cardiac size. CT revealed diffuse pulmonary micronodules and mild mediastinal adenopathy (Figure 1C). Pulmonary function testing (PFT) showed an obstructive ventilatory defect with impairment in gas exchange. Transbronchial biopsy showed multiple epithelioid granulomas involving the pulmonary parenchyma, without associated fibro-inflammatory reaction (Figure 1D). Special stains for acid-fast and fungal organisms were negative. She started prednisone $40 \mathrm{mg}$ daily, tapered to $7.5 \mathrm{mg}$ daily within 2 months. Chest CT 2 months later showed considerable improvement in ground-glass opacity and nodules with persistence of mild mediastinal adenopathy. PFT normalized, and adalimumab was started due to flaring RA. After 4 years of treatment with adalimumab, the pulmonary infiltrates have not recurred.

Patient 4. A 54-year-old woman with a history of juvenile erosive polyarticular RF-positive RA had progressive disability and deformity despite treatment with antiinflammatory agents and disease modifying antirheumatic drugs. In 1999 etanercept was begun, with significant improvement, eventually resulting in return to fulltime employment. In November 2004 she developed dyspnea and chest tightness without significant cough and with slight fever $\left(100.1^{\circ} \mathrm{F}\right)$. Chest radiograph showed hazy opacification of both lungs. Chest CT revealed patchy ground-glass opacities in upper and mid-lung zones, slight mediastinal adenopathy, and no pleural or pericardial effusions (Figure 1E). Transbronchial biopsy revealed focal interstitial chronic inflammation and one small poorly developed granuloma (Figure 1F). Bronchoalveolar lavage (BAL) yielded a lymphocyte-predominant effluent with a CD4:CD8 $\mathrm{T}$ cell ratio of 0.6 . Immunohistochemical staining showed the majority of lymphocytes were CD8+. Extensive studies for microbial organisms were all negative. Etanercept was discontinued and the chest radiograph normalized, along with resolution of pulmonary symptoms and normalization of PFT. Then RA flared severely and adalimumab was started, $40 \mathrm{mg}$ every other week. Signs and symptoms of RA again improved and pulmonary symptoms did not recur.
Tumor necrosis factor (TNF) regulates expression of adhesion molecules responsible for leukocyte migration ${ }^{1}$, and is critical for the formation and function of granulomas ${ }^{2}$. Consequently, reactivation and acquisition of new infections that are contained by a granulomatous host response (e.g., tuberculosis and histoplasmosis) are of particular concern with anti-TNF therapy $^{3,4}$. Pulmonary toxicity is not a well known side effect of etanercept, and most adverse pulmonary events during treatment with TNF antagonists are infectious ${ }^{5}$. There are 6 reported cases of noncaseating granulomatous inflammation in patients with RA treated with etanercept ${ }^{6-8}$, and one report of an individual with psoriatic arthritis developing pulmonary granulomas while taking etanercept ${ }^{9}$. Two additional reports link other TNF blockers with pulmonary granulomas in RA patients ${ }^{8-10}$. Onset of pulmonary sarcoidosis, described during treatment of ankylosing spondylitis (AS) with infliximab ${ }^{11}$, resolved with prednisone and discontinuation of the TNF blocker. Another patient with AS developed cutaneous sarcoidosis and hilar adenopathy while taking etanercept, which resolved when etanercept was discontinued ${ }^{12}$. Etanercept is not currently viewed as an attractive option for the treatment of sarcoidosis ${ }^{13}$. Other forms of pulmonary toxicities related to anti-TNF therapy have been suggested. Several reports link infliximab with worsening or new onset of interstitial pneumonia ${ }^{14-17}$. In one RA patient, adalimumab was linked to pulmonary fibrosis ${ }^{18}$. Among 39 patients who developed systemic vasculitis while receiving TNF antagonists, involvement of the lung ( 1 case) or the pleura ( 2 cases) was unusu$\mathrm{al}^{19}$. The appearance of a new granulomatous process during treatment with a TNF antagonist may seem surprising, given the role of TNF in formation of granulomas during infections such as tuberculosis ${ }^{20}$. However, it appears that although TNF-/- mice can localize a full spectrum of inflammatory cells in lung tissue during tuberculous infection, the precise functional organization of the granulomas is defective $\mathrm{e}^{21}$. In this model, both secreted and transmembrane TNF are essential for successful host defense $^{22}$. In one case we studied the BAL fluid CD4:CD8 ratio of lymphocytes. The finding of a CD4:CD8 ratio $<1.0$ is highly suggestive of hypersensitivity pneumonitis, but not sarcoidosis, which is associated with noncaseating pulmonary granulomata and a CD4:CD8 ratio $>123$. It is unclear whether the pulmonary infiltrates in our patients represented a reaction to etanercept itself or to an undefined trace contaminant. All patients improved with withdrawal of etanercept and the addition of prednisone, without use of antibiotics. This observation, along with the histopathologic features of the granulomas and BAL findings in one 
a
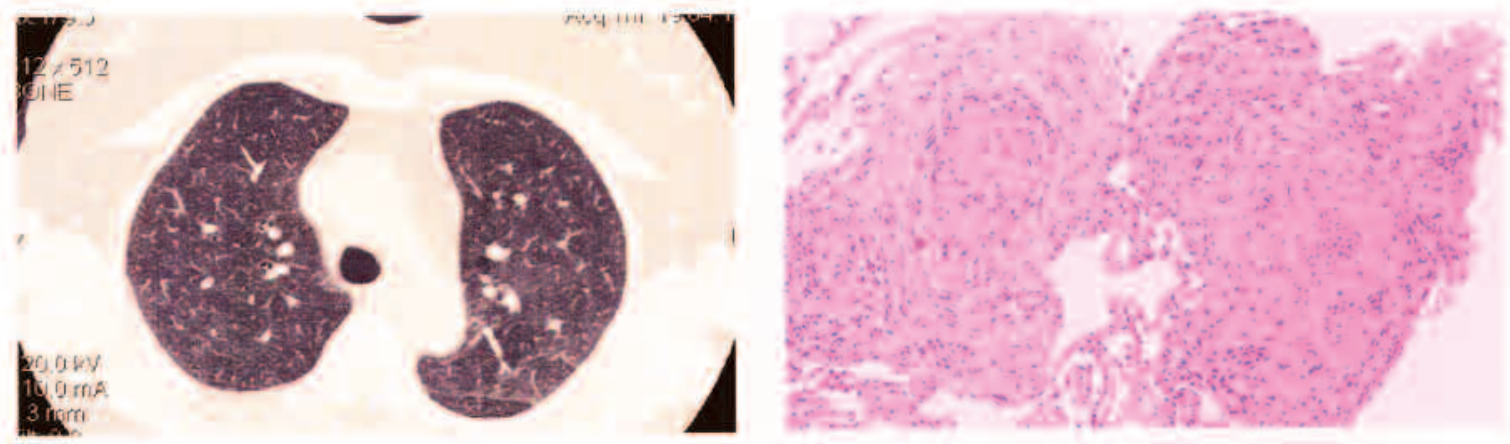

C
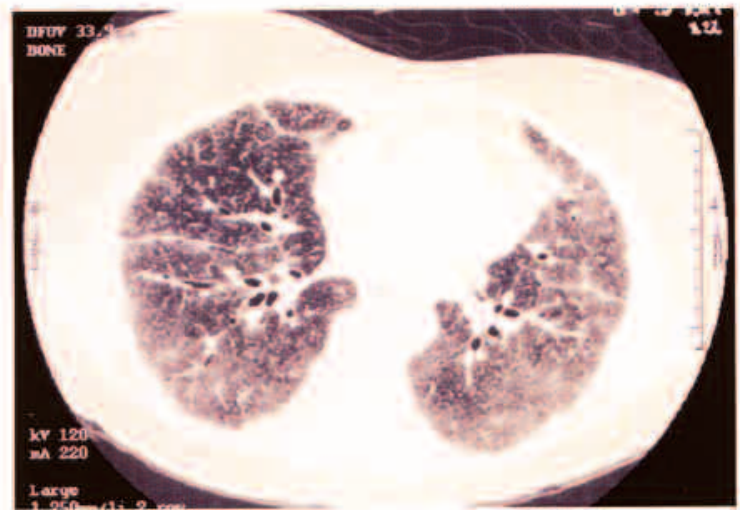

e
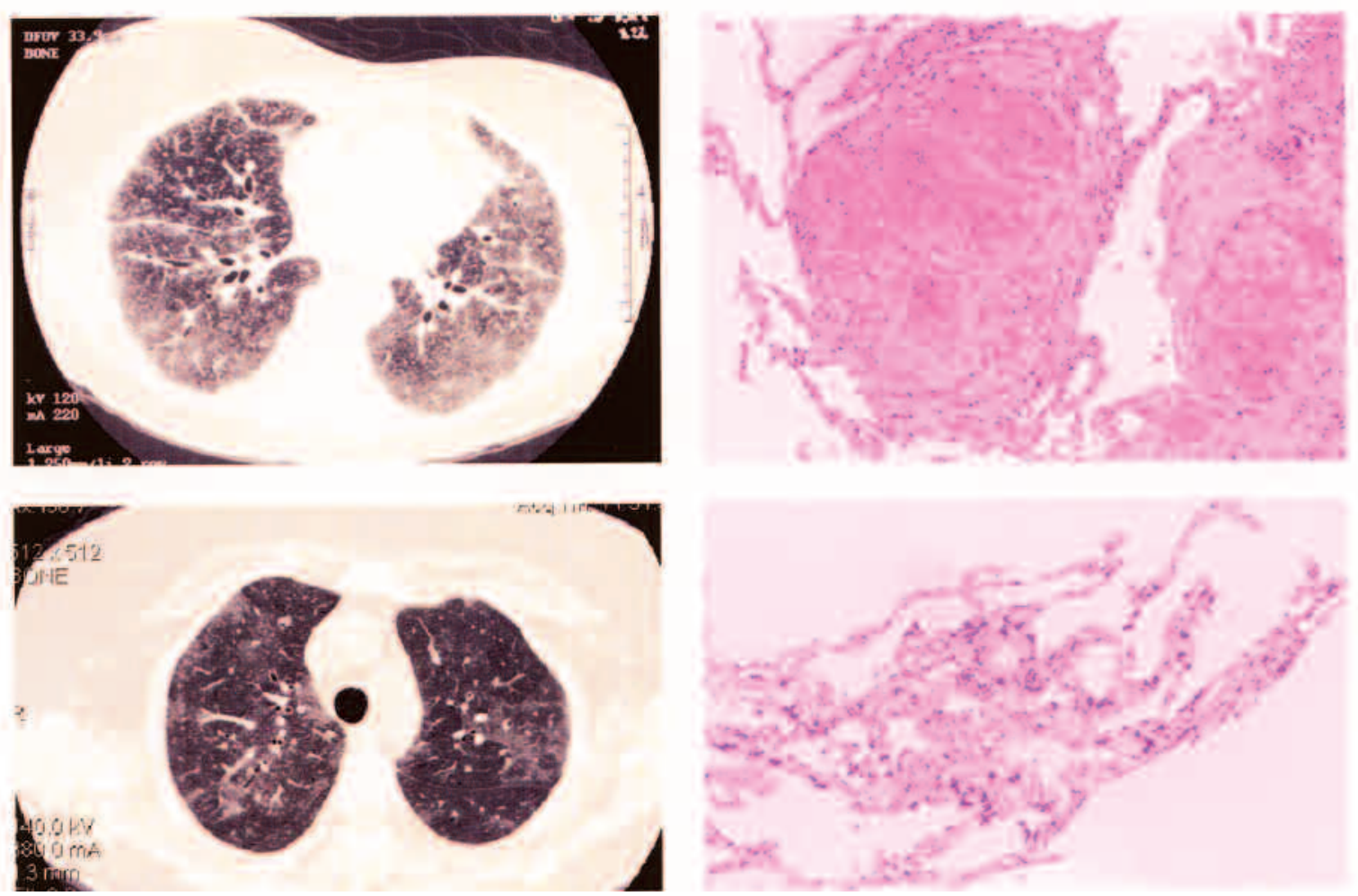

Figure 1. A. Bilateral ground-glass opacity, innumerable tiny nodules, and thickened bands of fibrosis in both lung bases. B. Transbronchial biopsy: non-necrotic granulomatous inflammation. C. Bilateral pulmonary micronodules and mild mediastinal adenopathy. D. Transbronchial biopsy: multiple epithelioid granulomas involving the pulmonary parenchyma. E. Confluent patchy ground-glass opacities in both upper and mid-lung zones bilaterally with slight mediastinal adenopathy. F. Transbronchial biopsy: focal interstitial chronic inflammation and one small poorly developed granuloma.

patient, suggests a drug effect. All 4 patients were subsequently treated with adalimumab, a monoclonal anti-TNF agent, with no recurrence of pulmonary toxicity. This helps to exclude the possibility that an occult infection was overlooked, and implies a drug-specific effect rather than a class effect. It is currently unclear why these 2 drugs might differ in their potential adverse effects. In the absence of infections, drug toxicity should be considered as a cause of pulmonary granulomatous inflammation in RA patients receiving etanercept.

VLADIMIR M. OGNENOVSKI, MD, Division of Rheumatology; TAMMY CLARK OJO, MD, Division of Pulmonary and Critical Care Medicine; DAVID A. FOX, MD, Division of Rheumatology, Department of Internal Medicine and Rheumatic Diseases Core Center, University of Michigan, Ann Arbor, Michigan, USA. Address reprint requests to Dr. D.A. Fox, Room 3918 Taubman Center, SPC 5358, 1500 East Medical Center Drive, Ann Arbor, MI 48109-5358. E-mail: dfox@umich.edu

\section{REFERENCES}

1. Choi EH, Panayi G. Cytokine pathways and joint inflammation in rheumatoid arthritis. New Engl J Med 2001;344:907-16.

2. Roach DR, Briscoe H, Saunders B, France MP, Riminton S, Britton WJ. TNF regulates chemokine induction essential for cell recruitment, granuloma formation, and clearance of mycobacterial infection. J Immunol 2002;168:4620-7.

3. Keane JS, Gershon RP, Wise E, Mirabile-Levens J. Tuberculosis associated with infliximab, a tumor necrosis factor alpha-neutralizing agent. New Engl J Med 2001;345:1098-104.

4. Flynn JL, Goldstein MM, Chan J, et al. Tumor necrosis factor-alpha is required in the protective immune response against Mycobacterium tuberculosis in mice. Immunity 1995;2:561-72.

5. Mutlu GM, Mutlu EA, Bellmeyer A, Rubinstein I. Pulmonary adverse events of anti-tumor necrosis factor-a antibody therapy. Am J Med 2006;119:639-46. 
6. Peno-Green L, Lluberas G, Kingsley T, Brantley S. Lung injury linked to etanercept therapy. Chest 2002;122:1858-60.

7. Yousem AS, Dacic S. Pulmonary lymphohistiocytic reactions temporally related to etanercept therapy. Modern Pathology 2005;18:651-55.

8. Bijkerk C, De Gendt C, De Jong A, Janssen M, Traksel R, Visser H. Non-tuberculous granulomatous inflammation linked to anti-tumor necrosis factor alpha therapy [abstract]. Ann Rheum Dis 2004;63 Suppl: 306.

9. Phillips K, Weinblatt M. Granulomatous lung diseases occurring during etanercept treatment. Arthritis Rheum 2005;53:618-20.

10. Varicka SR, Wettstein T, Speich R, Gaspert A, Bachli EB. Pulmonary granulomas after tumour necrosis factor alpha antagonist therapy. Thorax 2003;58:278-9.

11. O'Shea FD, Marras TK, Inman RD. Pulmonary sarcoidosis developing during infliximab therapy. Arthritis Rheum 2006;55:978-81.

12. Gonzalez-Lopez MA, Blanco R, Gonzalez-Vela MC, Fernandez-Llaca H, Rodreiquez-Valverde V. Development of sarcoidosis during etanercept therapy. Arthritis Rheum 2006;55:817-20.

13. White ES, Lynch JP III. Current and emerging strategies for the management of sarcoidosis. Expert Opin Pharmacother 2007;8:1293-311

14. Oster AJ, Chilvers ER, Somerville MF, et al. Pulmonary complications of infliximab therapy in patients with rheumatoid arthritis. J Rheumatol 2006;33:622-8.

15. Chatterjee S. Severe interstitial pneumonitis associated with infliximab therapy. Scand J Rheumatol 2004;33:276-7.

16. Tengstrand, BS, Engvall IL, Rydvald Y, Hafstron I. TNF blockade in rheumatoid arthritis can cause severe fibrosing alveolitis. Six case reports. Lakartidningen 2005;102:3788-90, 3793.

17. Kramer N, Chuzhin Y, Kaufman LD, Ritter JM. Rosenstein ED. Methotrexate pneumonitis after initiation of infliximab therapy for rheumatoid arthritis. Arthritis Rheum 2002;47:670-1.

18. Schoe A, vander Laan-Baalbergen NE, Huizinga TW, Breedveld FC, van Laar JM. Pulmonary fibrosis in a patient with rheumatoid arthritis treated with adalimumab. Arthritis Rheum 2006;55:157-9.

19. St. Marcoux B, De Bandt M. Vasculitides induced by TNFa antagonists: a study in 39 patients in France. Joint Bone Spine 2006;73:710-3.

20. Flynn JL, Goldstein MM, Chan J, et al. Tumor necrosis factor-a is required in the protective immune response against mycobacterium tuberculosis in mice. Immunity 1995;2:561-72.

21. Bean AGD, Roach D, Briscoe H, et al. Structural deficiencies in granuloma formation in TNF gene-targeted mice underlie the heightened susceptibilty to aerosol mycobacterium tuberculosis infection, which is not compensated for by lymphotoxin. J Immunol 1999;162:3504-11.

22. Saunders BM, Tran S, Ruuls S, Sedgwick JD, Briscoe H, Britton WJ. Transmembrane TNF is sufficient to initiate cell migration and granuloma formation and provide acute, but not long-term, control of mycobacterium tuberculosis infection. J Immunol 2005; 174:4852-9.

23. Welker L, Jorres RA, Costabel U, Magnussen H. Predictive value of BAL cell differentials in the diagnosis of interstitial lung diseases. Eur Respir J 2004;24:1000-6.

J Rheumatol 2008;35:11; doi:10.3899/jrheum.080383

\section{Anti-Citrullinated Protein Antibody Response Associated with Synovial Immune Deposits in a Patient with Suspected Early Rheumatoid Arthritis}

To the Editor:

Anti-citrullinated protein antibodies (ACPA) are highly specific for rheumatoid arthritis (RA) and precede the onset of clinical symptoms by several years, with increasing titers as patients approach disease onset ${ }^{1,2}$. The synovium is the primary site of pathology in RA, and ACPA are readily detectable in the synovial fluid and tissue of patients with $\mathrm{RA}^{3}$. The transition from asymptomatic autoimmunity to clinically detectable synovitis is not well understood. We describe the serological and synovial features of a young woman from a multi-case RA family who initially had asymptomatic autoimmunity, then subsequently developed clinical features suggestive of early RA.

An 18-year-old Native North American (Cree) woman from Central Canada was recruited to a study that aimed to identify high-risk family members of RA probands and follow them longitudinally for disease onset. This study was approved by the Research Ethics Board of the University of Manitoba, and by the Band Councils of the First Nations communities. At baseline she was asymptomatic and had an entirely normal joint examination. Within 6 months of enrollment she developed pain and stiffness in her left knee and left wrist. Examination revealed joint-line tenderness in these 2 joints, along with several small joints of the hands, although no effusion was detectable. She was suspected of having early RA and started taking hydroxychloroquine and naproxen. After informed consent, at that time she also underwent a Parker-Pearson synovial biopsy of the knee, per an established study protocol. With treatment, her symptoms rapidly improved, and within 3 months she spontaneously discontinued the medications, as she had become pregnant for the first time. She continued to be free of synovitis throughout the pregnancy. After delivering a healthy baby she once again developed tenderness and swelling in the left wrist and left knee, and was again given hydroxychloroquine and naproxen, with improvement in the symptoms over the ensuing 2 months. To date, her symptoms continue to be well controlled with this regimen.

The investigations at baseline had revealed that she was negative for $\operatorname{IgM}$ and $\operatorname{IgA}$ rheumatoid factor (RF), but was positive for anti-CCP2 (Eurodiagnostica) and anti-CCP3 (Inova) antibodies, at a titer of 52 and 38 units respectively. $\mathrm{C}$-reactive protein and erythrocyte sedimentation rate were in the normal range. HLA testing showed her to have the HLADRB $1 * 0901$ and *1402 alleles. Her serum samples were tested for ACPA isotypes (IgM, IgA, IgG1-4) using ELISA as described ${ }^{4}$. Anti-Sa was tested by ELISA as described ${ }^{5}$. Response to citrullinated fibrinogen (cit-fib), and 5 different linear citrullinated peptides, including C2 (vim), C3 (vim) derived from human vimentin, $\mathrm{C} 4(\mathrm{fb})$ and $\mathrm{C} 5(\mathrm{fb})$ derived from human fibrinogen, and C6 (en) derived from human enolase, were assessed by ELISA with 2 non-citrullinated peptides as controls. Cutoff level was established on the basis of the mean +2 standard deviations of the values obtained from testing 30 healthy Caucasian controls.

$\mathrm{RF}$ and acute-phase reactants remained negative throughout the study period. IgG1-ACPA was positive the first visit (151 AU), with increasing titers during followup (Figure 1). IgA-ACPA was initially negative, but became positive with increasing titers after symptom onset. IgM-ACPA, $\mathrm{IgG} 2, \mathrm{IgG} 3$, and $\mathrm{IgG} 4$ remained negative throughout the study period. After being initially negative, she developed increasing titers of antibodies against cit-fibrinogen, but remained negative for anti-Sa and all of the linear citrullinated peptides tested. These data suggest that onset of clinical synovitis was heralded by an expansion in ACPA isotype usage, along with epitope spreading to nonlinear cit-fibrinogen-associated antigens. Interestingly, as shown in Figure 1, the autoantibody levels continued to rise despite amelioration of the clinical symptoms with pregnancy. This observation implies that the clinical improvement typically seen during RA pregnancy may not necessarily reflect an attenuation of the underlying autoimmune mechanisms, at least at this early stage of the process.

In contrast to the findings reported in studies of early RA, the synovium demonstrated normal sublining architecture and minimal microvascular changes. The synovial lining layer was markedly abnormal throughout multiple samples, with the lining cells appearing to float in an amorphous extracellular matrix (Figure 2A). Immunoperoxidase staining revealed the presence of an occasional CD3-positive cell without aggregates, but no CD19 cells. CD68 and CD55 staining were present in the lining layer, and 


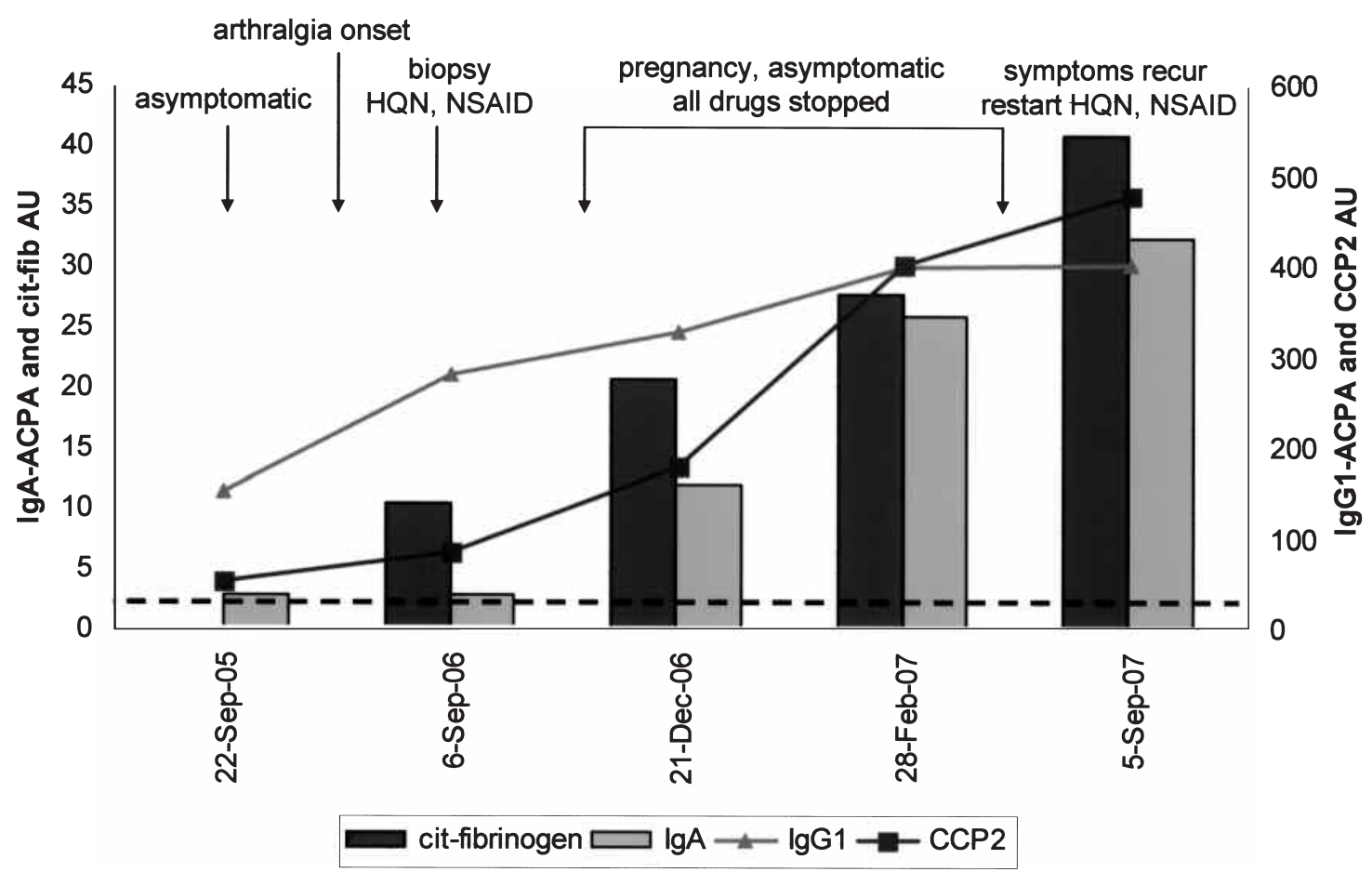

Figure 1. Development of ACPA response over a 2-year period in relation to clinical features in suspected early RA. Levels of all ACPA isotypes and specificity are shown as arbitrary units (AU), with levels of IgA-ACPA and anti-citrullinated-fibrinogen (cit-fib) shown on Y1 axis, and levels of IgG1-ACPA and anti-CCP2 shown on Y2 axis. Approximate cutoff level determined using 30 healthy controls is indicated by broken line. There is an increase in the titers of all ACPA over the study period, with IgA-ACPA and anti-cit-fib both becoming positive after onset of articular symptoms.

CD68-positive cells were scattered throughout the sublining. Staining using a polyclonal anti-citrulline antibody (AP064, GemacBio) to detect citrullinated proteins demonstrated intense staining of the synovial lining cells (Figure 2B). Immunofluorescence studies showed staining of the lining layer for $\operatorname{IgG}, \operatorname{IgA}, \mathrm{C} 3$, and fibrin (Figure 2C), suggesting that the synovial lining layer may have been the target of an antibody-mediated immune response with complement activation and deposition. Although the specific target of this immune response was not directly tested, the colocalization of citrullinated antigens in lining cells with the immune deposits is consistent with the possibility that the response is directed towards a citrullinated antigen(s). TdT-mediated dUTP-biotin nick-end labeling (TUNEL) demonstrated extensive staining of the synovial lining cells (Figure 2D) compared to that seen in a normal synovial membrane (data not shown), indicating that the lining cells were undergoing widespread apoptosis.

We describe a case where there was a transition from asymptomatic autoimmunity to clinically evident synovitis. At this point, it is not possible to determine with certainty whether this patient's synovitis represents the earliest clinical evidence of RA, since she has yet to meet the American College of Rheumatology criteria set. On the other hand, it is possible that the very early use of antimalarials may indeed serve to prevent the full expression of the clinical RA syndrome. This has been shown with the use of methotrexate in anti-cyclic citrullinated peptide-positive patients with undifferentiated arthritis ${ }^{6}$. The serological evolution and synovial features are consistent with the hypothesis that isotype expansion and epitope spreading of ACPA responses to synovial autoantigens are associated with the onset of synovitis in an individual who is genetically susceptible to RA.

ANNEMIEK WILLEMZE, MSc; ANDREEA IOAN-FACSINAY, PhD, Department of Rheumatology, Leiden University Medical Center, Leiden,
The Netherlands; HANI EL-GABALAWY, MD, Arthritis Centre, University of Manitoba, Winnipeg, Manitoba, Canada; Address reprint requests to Dr. El-Gabalawy. E-mail: elgabalh@cc.umanitoba.ca

\section{REFERENCES}

1. Nielen MM, van Schaardenburg D, Reesink HW, et al. Specific autoantibodies precede the symptoms of rheumatoid arthritis: a study of serial measurements in blood donors. Arthritis Rheum 2004;50:380-6.

2. Rantapaa-Dahlqvist S, de Jong BA, Berglin E, et al. Antibodies against cyclic citrullinated peptide and IgA rheumatoid factor predict the development of rheumatoid arthritis. Arthritis Rheum 2003;48:2741-9.

3. Caspi D, Anouk M, Golan I, et al. Synovial fluid levels of anti-cyclic citrullinated peptide antibodies and IgA rheumatoid factor in rheumatoid arthritis, psoriatic arthritis, and osteoarthritis. Arthritis Rheum 2006;55:53-6.

4. Verpoort KN, Jol-van der Zijde CM, Papendrecht-van der Voort EA, et al. Isotype distribution of anti-cyclic citrullinated peptide antibodies in undifferentiated arthritis and rheumatoid arthritis reflects an ongoing immune response. Arthritis Rheum 2006;54:3799-808.

5. Boire G, Cossette P, de Brum-Fernandes AJ, et al. Anti-Sa antibodies and antibodies against cyclic citrullinated peptide are not equivalent as predictors of severe outcomes in patients with recent-onset polyarthritis. Arthritis Res Ther 2005;7:R592-603.

6. van Dongen H, van Aken J, Lard LR, et al. Efficacy of methotrexate treatment in patients with probable rheumatoid arthritis: a double-blind, randomized, placebo-controlled trial. Arthritis Rheum 2007;56:1424-32.

J Rheumatol 2008;35:11; doi:10.3899/jrheum.080424 
A
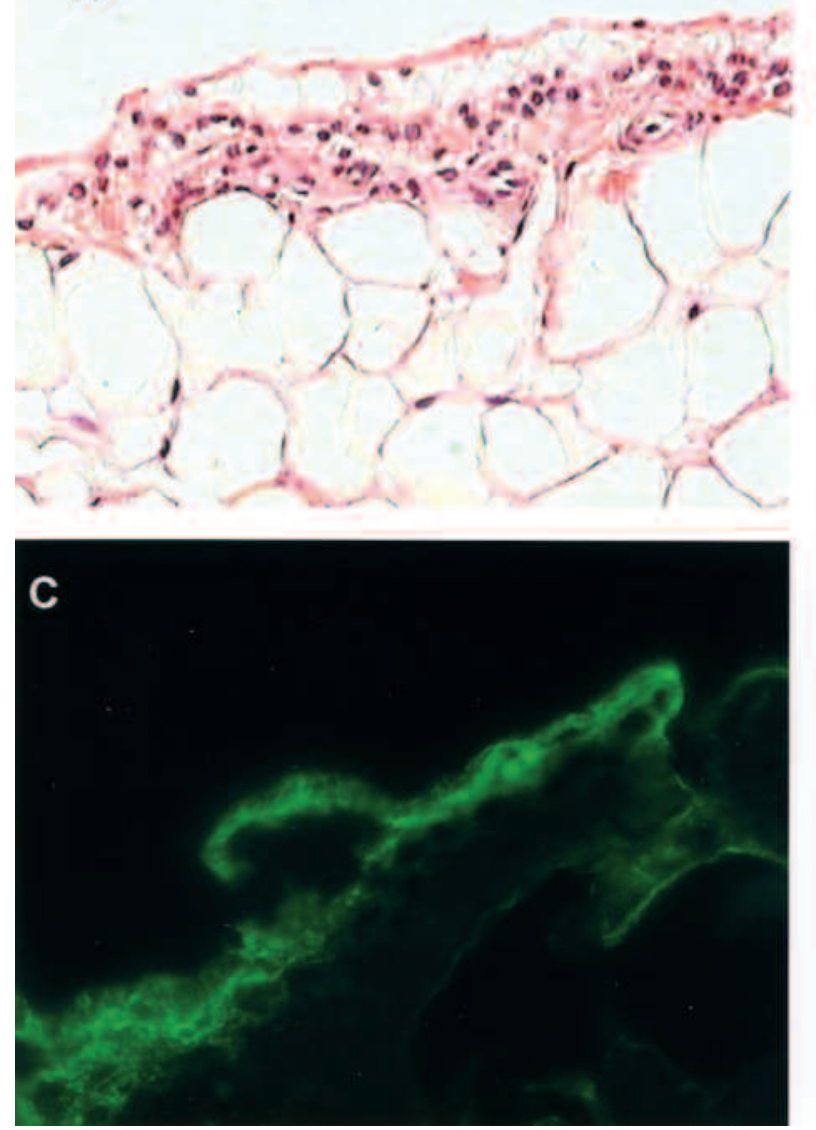

B
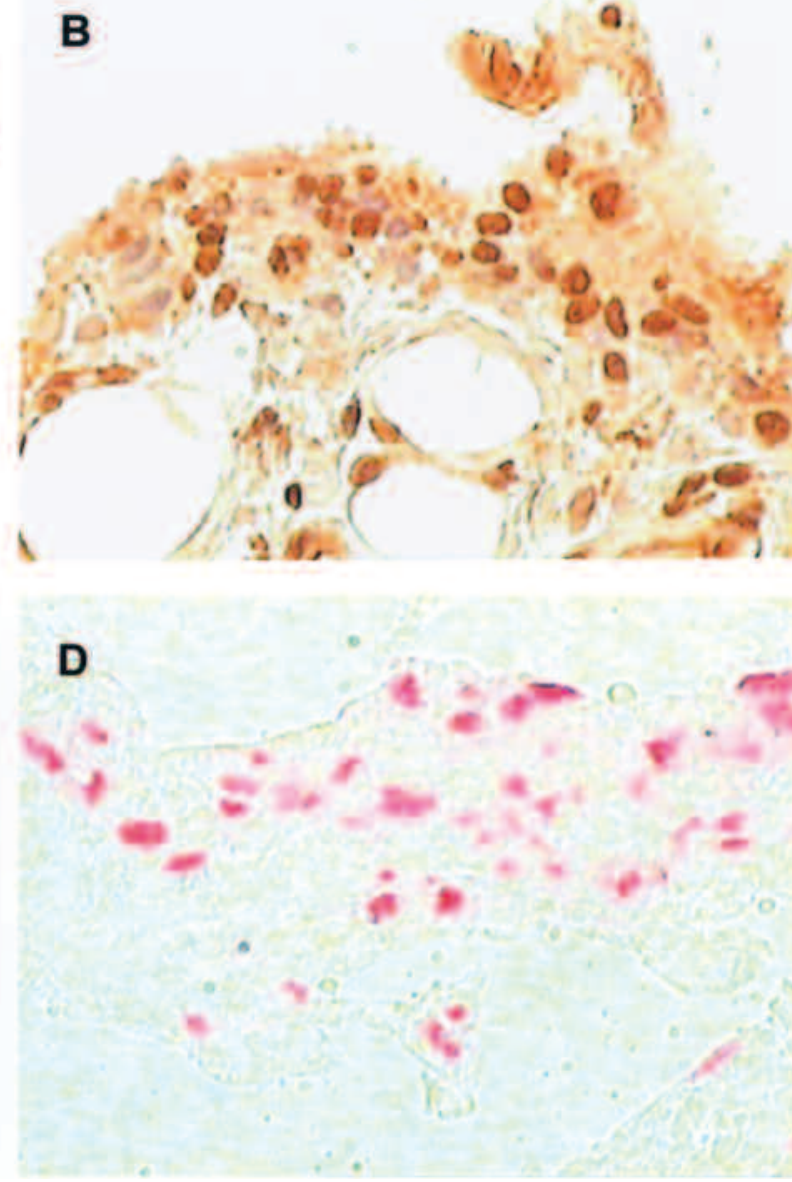

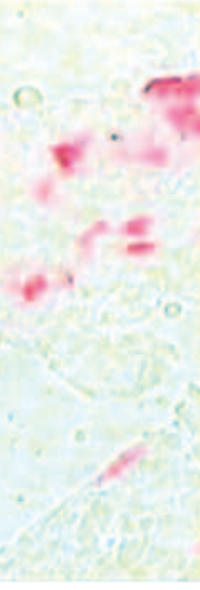

Figure 2. Synovial tissue analysis of biopsy material from a symptomatic knee joint shortly after onset of articular symptoms. A. H\&E light microscopy showing marked disruption of the synovial lining cell layer. Lining cells appear to be floating in an amorphous extracellular matrix. Sublining stroma is relatively unremarkable with minimal evidence of inflammatory infiltration. B. Intracellular citrullinated antigens are detected by intense staining of the synovial lining cells using a polyclonal anticitrulline antibody. There is less intense staining of the surrounding matrix. C. Immunofluoresence staining of synovial tissue for C3 showing positive staining in lining layer. Similar results were seen with IgG, IgA, and fibrin staining. D. Synovial lining cells exhibit evidence for widespread apoptosis as detected by TUNEL staining. Original magnification $\times 200$ for $\mathrm{A}$, and $\times 400$ for $\mathrm{B}, \mathrm{C}, \mathrm{D}$.

\section{Therapeutic Effects of Alendronate on Bone Erosion and Atrophy in a Patient with Rheumatoid Arthritis and Hepatitis C Virus Infection}

\section{To the Editor:}

Rheumatoid arthritis (RA) is a chronic systemic inflammatory disease associated with progressive disability and serious comorbidities ${ }^{1}$. Disease modifying antirheumatic drugs (DMARD) are now widely used in patients with RA, and treatment of RA with DMARD can prevent joint destruction $^{2}$. Bisphosphonates are potent inhibitors of bone resorption and are widely used for osteoporosis and corticosteroid-induced osteoporosis ${ }^{3}$ in patients with RA. A recent study showed that bisphosphonates affected inflammation as well as resorption in a rat model of arthritis ${ }^{4}$. This background led us to administer alendronate to a patient with RA.

We describe a 38-year-old Japanese man with a 3-month history of acute-onset arthritis. He was referred to the Institute of Rheumatology, Tokyo Women's Medical University, in June 2006. A diagnosis of chronic active hepatitis due to hepatitis $\mathrm{C}$ virus (HCV) infection had been made when he was 35 years old. He had no other relevant medical history and was taking no medication. At the first visit, he had tenderness and swelling in several joints of the right hand; however, there were no symptoms in other joints. Blood tests showed an increased concentration of C-reactive protein (CRP; $0.62 \mathrm{mg} / \mathrm{dl}$ ) and an increased erythrocyte sedimentation rate (ESR; $53 \mathrm{~mm} / \mathrm{h}$ ). He did not have anemia (hemoglobin $14.8 \mathrm{~g} / \mathrm{dl}$ ) and the white blood cell count was also normal $\left(6.6 \times 10^{3} / \mu 1\right.$ : $59.3 \%$ neutrophils, $29.6 \%$ lymphocytes, $4.7 \%$ eosinophils). Laboratory tests revealed liver dysfunction due to chronic $\mathrm{HCV}$ infection; aspartate aminotransferase and alanine aminotransferase levels were 151 and $254 \mathrm{IU} / \mathrm{ml}$, respectively. Laboratory tests of renal function yielded normal findings. Rheumatoid factor and anti-cyclic citrullinated peptide antibody were present $(20 \mathrm{IU} / \mathrm{ml}$ and $>100 \mathrm{U} / \mathrm{ml}$, respectively); however, antinuclear antibody and cryoglobulin were absent. Radiography of the right hand at the first visit showed bone erosions and severe bone atrophy (Figure 1). Our diagnosis was early-stage RA, as defined by the 1987 American College of Rheumatology classification criteria ${ }^{5}$, with chronic active hepatitis due to $\mathrm{HCV}$ infection. Initially, we refrained from using immunosuppressants to treat the RA because of the possibility of worsening the HCV-related hepatitis. We first administered oral alendronate for the bone atrophy. Unexpectedly, after 2 weeks of monotherapy with $5 \mathrm{mg}$ oral alendronate daily, there were clinical improvements, including reductions in joint

Personal non-commercial use only. The Journal of Rheumatology Copyright @ ${ }^{2008}$. All rights reserved. 

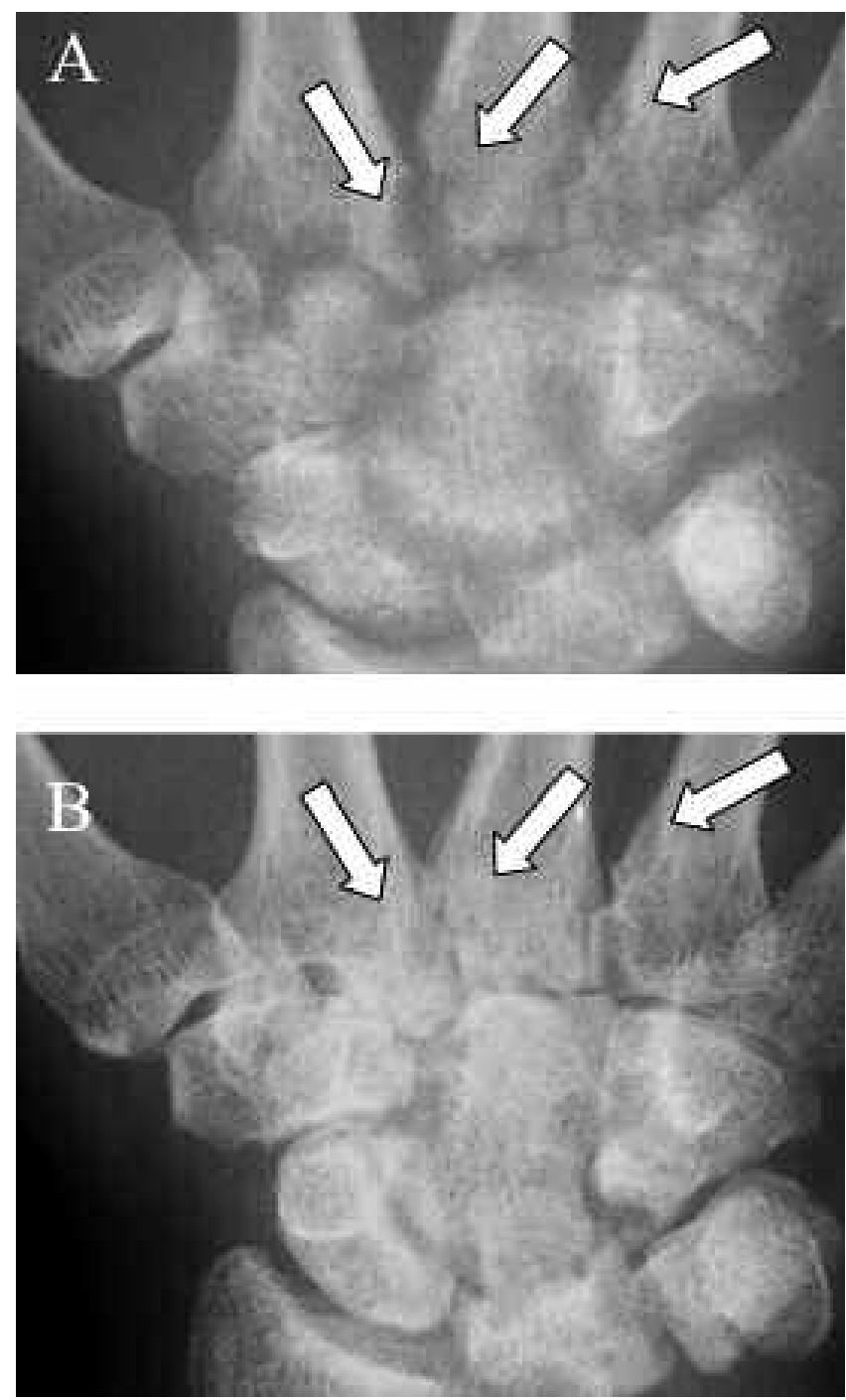

Figure 1. Radiography of the patient's right hand (A) at the first visit and (B) after alendronate therapy. (A) Bone erosion and atrophy are visible (arrows); (B) erosion and atrophy are improved (arrows).

swelling and tenderness. Therefore, we did not add any DMARD to the alendronate therapy. After 4 months of oral alendronate monotherapy, arthritis symptoms in the right hand had almost disappeared. CRP levels and ESR were normal $(0.03 \mathrm{mg} / \mathrm{dl}$ and $9 \mathrm{~mm} / \mathrm{h})$, and liver function had not deteriorated. Radiography showed healing of bone erosions and bone atrophy (Figure 1). Flexion of the right wrist improved from $0^{\circ}$ to $60^{\circ}$ during the 4 months of treatment.

A study in rats with adjuvant arthritis showed that alendronate is effective against not only loss of bone mineral density but also inflammationassociated bone damage ${ }^{4}$. Our findings correlate well with those of the previous study ${ }^{4}$ with regard to the efficacy of alendronate against inflammation-associated bone damage. Ours is the first report of a patient with early RA whose active arthritis improved and whose bone erosions were repaired with alendronate monotherapy. Alendronate might have an inhibitory effect on inflammation in patients with RA.

Considering the pathogenesis of RA, both generalized bone loss and bone damage must receive attention. Although methotrexate (MTX) has been proved effective in reducing focal bone damage ${ }^{2}$, there is a tendency to avoid using DMARD, including MTX, for RA patients with virus-associated hepatitis because DMARD might cause the deterioration of virus- associated hepatitis ${ }^{6}$. For patients who cannot be treated with MTX or other DMARD, new effective strategies are needed for the prevention of focal bone damage; bisphosphonate therapy might have a positive effect on not only generalized bone loss but also the osteoclasts that are the culprits in focal damage. Bisphosphonates are powerful inhibitors of osteoclastic bone resorption and are widely used to manage diseases characterized by bone loss.

Bisphosphonates are classified into 2 main categories: aminobisphosphonates and nonaminobisphosphonates. The aminobisphosphonate alendronate, particularly when given intravenously, sensitizes macrophages to inflammatory stimuli and can induce an acute inflammatory reaction, with fever and other flu-like symptoms, which resolve within 48 hours ${ }^{7}$. Aminobisphosphonates also inhibit angiogenesis in tumor models. RA is a chronic inflammatory disease associated with increased synovial vascularity. Bisphosphonate therapy may be a new strategy for inhibiting angiogenic factors in disease models of $\mathrm{RA}^{8}$. A recent study showed that zoledronic acid, a potent bisphosphonate, was highly effective against damage to bone and joint structures in a model of collagen-induced arthritis 9 . Thus, clinical trials of bisphosphonates in RA have generally demonstrated suppressive effects on generalized bone loss but not on focal bone erosions ${ }^{10}$.

We showed that alendronate monotherapy was effective against bone erosions in a patient with RA. However, in previous study, protection against structural joint damage was reported only with zoledronic acid ${ }^{10}$. We postulated that alendronate might be an effective therapy for inhibition of angiogenesis and osteoclastic activities. Alendronate is effective in patients with early RA who cannot be treated with DMARD. If alendronate proves to be useful in patients with early-stage RA, more studies should be conducted to determine whether routine bisphosphonate therapy should be started at the time of diagnosis of RA in patients who cannot be treated with DMARD, including MTX.

Alendronate may exert not only an antiosteoporotic effect but also an antiinflammatory effect in patients with RA. Thus, alendronate may be a good therapy for inhibiting bone destruction in patients with RA.

MAKOTO SOEJIMA, MD, PhD; YASUSHI KAWAGUCHI, MD, PhD; MASAKO HARA, MD, PhD; SEIJI SAITO, MD, PhD; NAOYUKI KAMATANI, MD, PhD; HISASHI YAMANAKA, MD, PhD, Institute of Rheumatology, Tokyo Women's Medical University, 10-22 Kawada-cho, Shinjuku-ku, Tokyo 162-0054, Japan. Address reprint requests to Dr. Kawaguchi; E-mail: y-kawa@ior.twmu.ac.jp

\section{REFERENCES}

1. Gabriel SE, Crowson CS, O'Fallon WM. The epidemiology of rheumatoid arthritis in Rochester, Minnesota, 1955-1985. Arthritis Rheum 1999;42:415-20.

2. Ikari K, Momohara S. Images in clinical medicine. Bone changes in rheumatoid arthritis. N Engl J Med 2005;353:e13.

3. Phillips K, Aliprantis A, Coblyn J. Strategies for the prevention and treatment of osteoporosis in patients with rheumatoid arthritis. Drugs Aging 2006;23:773-9.

4. Harada H, Nakayama T, Nanaka T, Katsumata T. Effects of bisphosphonates on joint damage and bone loss in rat adjuvant-induced arthritis. Inflamm Res 2004;53:45-52.

5. Arnett FC, Edworthy SM, Bloch DA, et al. The American Rheumatism Association 1987 revised criteria for the classification of rheumatoid arthritis. Arthritis Rheum 1988;31:315-24.

6. Palazzi C, Olivieri I, Cacciatore P, Pennese E, D’Amico E. Management of hepatitis $\mathrm{C}$ virus-related arthritis. Exp Opin Pharmacother 2005;6:27-34

7. Santini D, Fratto ME, Vincenzi B, La Cesa A, Dianzani C, Tonini G. Bisphosphonate effects in cancer and inflammatory diseases: in vitro and in vivo modulation of cytokine activities. BioDrugs 2004;18:269-78.

8. Szekanecz Z, Koch AE. Mechanisms of disease: angiogenesis in inflammatory diseases. Nat Clin Pract Rheumatol 2007;3:635-43. 
9. Sims NA, Green JR, Glatt M, et al. Targeting osteoclasts with zoledronic acid prevents bone destruction in collagen-induced arthritis. Arthritis Rheum 2004;50:2338-46.

10. Jarrett SJ, Conaghan PG, Sloan VS, et al. Preliminary evidence for a structural benefit of the new bisphosphonate zoledronic acid in early rheumatoid arthritis. Arthritis Rheum 2006;54:1410-4.

J Rheumatol 2008;35:11; doi:10.3899/jrheum.080201

\section{Indirect Evidence for the Efficacy of Methotrexate in Diffuse Systemic Sclerosis}

\section{To the Editor:}

The use of methotrexate (MTX) in the treatment of systemic sclerosis (SSc) remains controversial. We provide indirect evidence for the efficacy of MTX in 3 patients with diffuse SSc who had good response of skin scores to MTX, significant worsening after stopping MTX, and subsequent improvement with reinstitution of MTX.

Patients were 39 to 51 years old at reported onset of skin thickening. The initial modified Rodnan skin scores (mRSS) were all $\geq 20$. All patients had Raynaud's phenomenon and joint and gastrointestinal (GI) manifestations.

Patient 1 was positive for antinuclear antibody (ANA, speckled), but negative for anticentromere and antitopoisomerase-I antibodies. MTX (maximum $20 \mathrm{mg} / \mathrm{wk}$ ) and penicillamine $(500 \mathrm{mg} /$ day) were started at the first visit, but the latter was stopped after 8 months.

Patient 2 had Barrett's esophagus and recurrent bleeding from gastric vascular ectasia. Other comorbidities included severe aortic stenosis and coronary artery disease. ANA was positive (speckled and nucleolar). Treatment with cyclosporine A ( $2.5 \mathrm{mg} / \mathrm{kg} /$ day $)$ for nearly 2 years was ineffective. MTX (maximum $20 \mathrm{mg} / \mathrm{wk}$ ) was then commenced, overlapping with cyclosporine A for 4 months.

Patient 3 was positive for antitopoisomerase-I antibody and had digital ulceration, digital resorption, arthritis, and mild pulmonary fibrosis. She was initially treated with penicillamine $(250 \mathrm{mg} /$ day $)$ and switched to MTX (maximum $15 \mathrm{mg} / \mathrm{wk}$ ) 4 years after disease onset.

The mRSS was compared over 3 time periods: (1) first MTX treatment; (2) MTX discontinuation; (3) second MTX treatment. The change in mRSS was calculated for each time period using the peak or trough mRSS within 6 months of starting or stopping MTX. The percentage change in mRSS (expressed over the baseline value for each period) and the rate of change/year were calculated. A clinically significant change in mRSS was defined as $\geq 30 \%$ or rate of change $\geq 5$ units/year ${ }^{1,2}$.

All patients had $>30 \%$ mRSS improvement (rate of change -3.1 to -4.3 units/yr) and were taking MTX for 2.0 to 5.3 years (period 1). In patients 2 and 3, MTX was stopped (after the dose had been slowly reduced) for about 6 months (period 2) before the mRSS increased from 20 to 32 and 13 to 29 , respectively. MTX had been discontinued in Patient 1 for 2.4 years before the mRSS progressed from 6 to 17, after nearly 9 years of disease.

All patients responded to retreatment with MTX (mean mRSS decrease $79.5 \%$, mean rate of change -6.7 units/yr) with sustained improvement. Patient 3 also received low-dose prednisone ( $<5 \mathrm{mg}$ /day) for 10 months for arthritis, but this was unlikely to have resulted in the subsequent marked improvement in skin score. At last evaluation, MTX had been discontinued in all patients for 2 to 6 months, without worsening of skin scores (final mRSS between 4 and 6 ).

The use of MTX in SSc has been controversial. Two randomized placebo-controlled trials showed trends in favor of $\mathrm{MTX}^{3,4}$. In a small study of 29 patients with SSc, the MTX treated group showed favorable response as determined by a composite endpoint of skin-score response, diffusion capacity, or general well-being at 24 weeks. Analysis of separate variables showed a trend towards a minimal improvement of skin scores in the MTX group at 24 weeks (total skin score $-0.7 ; p=0.06)^{3}$. In another study ${ }^{4}$, MTX resulted in modest improvement of mRSS at 1 year $(-4.3$ in MTX group and 1.8 in placebo group; $\mathrm{p}<0.009)$. Both studies were small and would have been underpowered to detect false-negative results. Additionally, the doses of MTX used were low relative to current practice. It remains to be evaluated whether higher doses of MTX (> $15 \mathrm{mg} / \mathrm{wk}$ ) would have resulted in greater efficacy.

Although our case report does not directly address the efficacy of MTX in SSc, 2 observations are notable. (1) Skin scores in all patients responded to MTX (15-20 mg/wk) with > 30\% improvement in the 2 treatment periods. One might argue that the natural history of the disease resulted in spontaneous regression of skin scores, as was first reported by Black, et $a l^{5}$. However, significant worsening of mRSS ( $\geq 30 \%$ ) with MTX cessation suggests that MTX may have played a role in suppressing skin progression. (2) In Patient 1, MTX was stopped for 2 years, with stable skin scores before mRSS progressed from 6 to 17 after nearly 9 years of disease. This suggests that a subgroup of patients may have biphasic disease.

Our cases thus provide indirect evidence for the efficacy of MTX in the treatment of dSSc. Although our report of 3 patients is subject to reporting bias and uncontrolled observations, it serves as an impetus for prospective randomized controlled trials involving larger numbers of patients and higher doses of MTX to evaluate its efficacy in early diffuse SSc.

ANDREA H.L. LOW, BMBS, MRCP(UK), FAMS (Rheumatology), Clinical Fellow; PETER LEE, MD, FRCPC, FRACP, Professor of Medicine, Department of Medicine, Division of Rheumatology, University of Toronto, Mt. Sinai Hospital, Toronto, Canada. Address reprint requests to Dr. A. Low, Joseph and Wolf Lebovic Building, Main Floor, Room 2-004, Box 9, 60 Murray Street, Toronto, Ontario M5T 3L9, Canada.

\section{REFERENCES}

1. Steen VDM, Medsger TA Jr. Improvement in skin thickening in systemic sclerosis associated with improved survival. Arthritis Rheum 2001;44:2828-35.

2. Gazi H, Pope JE, Clements P, et al. Outcome measurements in scleroderma: results from a delphi exercise. J Rheumatol 2007;34:501-9.

3. van den Hoogen FH, Boerbooms AM, Swaak AJ, Rasker JJ, van Lier HJ, van de Putte LB. Comparison of methotrexate with placebo in the treatment of systemic sclerosis: a 24 week randomized double-blind trial, followed by a 24 week observational trial. Br J Rheumatol 1996;35:364-72.

4. Pope JE, Bellamy N, Seibold JR, et al. A randomized, controlled trial of methotrexate versus placebo in early diffuse scleroderma. Arthritis Rheum 2001;44:1351-8.

5. Black C, Dieppe P, Huskisson T, Hart FD. Regressive systemic sclerosis. Ann Rheum Dis 1986;45:384-8.

J Rheumatol 2008;35:11; doi:10.3899/jrheum.080492

\section{Hepatotoxicity Associated with Etanercept in Psoriatic Arthritis}

To the Editor:

We were interested to read the recent case report on granulomatous hepatitis associated with etanercept therapy in a patient with rheumatoid arthritis (RA) ${ }^{1}$. We have also experienced hepatotoxicity with etanercept, although in a patient with psoriatic arthritis (PsA).

A 50-year-old woman had a 20-year history of pustular psoriasis and PsA including arthritis mutilans. Psoriasis had been treated with combinations of topical and systemic drugs, including retinoids. Various nonsteroidal antiinflammatory drugs and disease-modifying antirheumatic drugs (DMARD) had been poorly tolerated or not effective. Episodes of toxicity included suspected allergic reactions (ibuprofen), raised transaminases (methotrexate), renal impairment (cyclosporine), and pancytopenia (azathioprine). Several courses of systemic steroids were unhelpful.

The patient's general health and mobility had deteriorated, and frequent 
relapses of psoriasis required repeated hospital admissions. Medical history included diet-controlled diabetes mellitus and hypercholesterolemia: complex social background, poor treatment compliance, and irregular outpatient clinic attendance added to the difficult clinical situation.

In September 2005 she was admitted with a further exacerbation of both psoriasis and arthritis, with severe generalized pain in her joints. Medication for the previous 3 months included calcipotriol cream, epaderm ointment, folic acid, ferrous sulfate, amitriptyline $50 \mathrm{mg}$ od, morphine sulfate (MST) $40 \mathrm{mg}$ bd, nitrazepam, omeprazole, and atorvastatin $80 \mathrm{mg}$, but no recent DMARD. Assessment included Disease Activity Score (DAS) 7.20 and Psoriasis Area and Severity Index (PASI) 47.5 (0-72). She therefore fulfilled the UK eligibility criteria for anti-tumor necrosis factor (TNF) therapy with no exclusions. Baseline biochemistry was normal (Figure 1) apart from low albumin, and C-reactive protein (CRP) of $128 \mathrm{mg} / \mathrm{l}$, and she had hypochromic macrocytic anemia with normal ferritin, B12, and folate. Etanercept was commenced at $50 \mathrm{mg}$ once weekly subcutaneously (weight $56 \mathrm{~kg}$ ) during her hospital stay (Figure 1).

After the fourth dose there was marked clinical improvement, especially of psoriasis, and CRP fell to $29 \mathrm{mg} / \mathrm{l}$. She then became unwell with nausea and abnormal liver function tests (Figure 1), together with CRP of 175 $\mathrm{mg} / \mathrm{l}$. She had a suspected urinary tract infection, although no source of infection was proven. Broad-spectrum antibiotics were given and her CRP fell to $23 \mathrm{mg} / \mathrm{l}$. She remained unwell with continuing weight loss to 37.7 $\mathrm{kg}$, and deteriorating liver function. Alcohol intake was excluded and abdominal ultrasound was unremarkable. Supportive treatment included intravenous fluids and nasogastric feeding. Due to the possibility of druginduced hepatitis, etanercept, atorvastatin, and amitriptyline were all discontinued and MST dosage was reduced.

Her clinical condition and liver function tests improved over 2 to 4 weeks, although her psoriasis worsened. After 2 months she was discharged with normal blood results, still off suspected drugs. Blood tests remained normal, so atorvastatin $80 \mathrm{mg}$ was reintroduced by her general practitioner due to resistant hypercholesterolemia (total cholesterol 6.9 $\mathrm{mmol} / \mathrm{l}$, triglycerides $2.3 \mathrm{mmol} / \mathrm{l}$ ) and etanercept was restarted after 3 months at a reduced dose of $25 \mathrm{mg}$ once a week (weight $47.8 \mathrm{~kg}$ ). Two months later her skin as well as mobility and joint pains showed a dramatic improvement. Her PASI score dropped to only 0.7: DAS at 1 month was 2.44 although it rose to 5.0 at 3 months. Fortnightly liver function tests and full blood count were normal apart from a slight rise in alkaline phosphatase. Due to noncompliance with appointments and blood monitoring her anti-TNF was subsequently stopped again, and she has been lost to followup.

Patients prescribed a TNF- $\alpha$ blocker without DMARD are only recommended to have monitoring blood tests at baseline and 3-monthly, and may be followed up in the community. Our patient developed the presumed drug-induced hepatitis within 1 month, diagnosed when she was an inpatient: this could have been missed as an outpatient. This differs from the reported case who had taken etanercept for 12 months before hepatitis occurred.

Drug-induced toxicity may be dose-related. Whereas the standard adult dose is $25 \mathrm{mg}$ twice weekly or $50 \mathrm{mg}$ once weekly, in children the dose of etanercept is tailored to the weight $(400 \mu \mathrm{g} / \mathrm{kg}$ twice weekly). Thus at 56 $\mathrm{kg}$, our patient's appropriate dose was $22.5 \mathrm{mg}$ twice weekly, and at her lowest weight of $37.7 \mathrm{~kg}, 15 \mathrm{mg}$ twice weekly. We rechallenged her with a reduced dose of only $25 \mathrm{mg}$ weekly, and this was still effective.

Hepatotoxicity with DMARD may be more common in PsA than RA. Raised transaminases occurring while patients are taking both anti-TNF drugs and methotrexate are difficult to interpret. Toxicity of anti-TNF drugs varies in different diseases and there is some evidence of hepatotoxicty of infliximab in both PsA and ankylosing spondylitis ${ }^{2-5}$. There is no doubt that in the short term, etanercept is effective in PsA ${ }^{6,7}$, although other biologics are also now available for psoriasis. The hepatotoxicity in this case may well have been multifactorial with the presumed intercurrent infection and interactions with other drugs. Side effects of biologics may vary in different diseases, and vigilance remains essential.

ALISON M. LEAK, MD, FRCP; BLANCA RINCON-AZNAR, LMS, Department of Rheumatology, Queen Elizabeth the Queen Mother Hospital, Ramsgate Road, Margate, Kent, CT9 4AN, UK. Address reprint requests to Dr. Leak. E-mail: alison.leak@ekht.nhs.uk

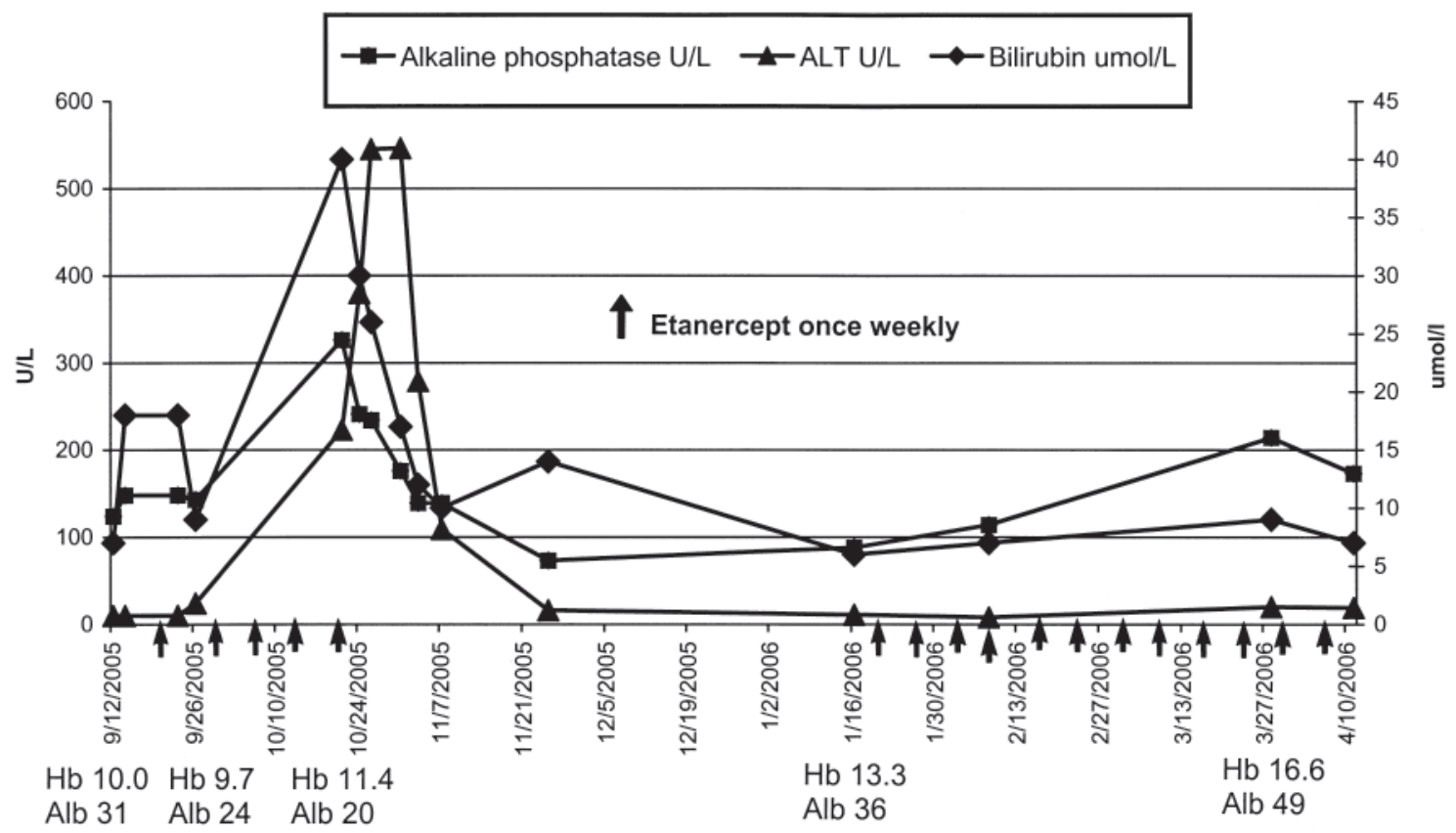

Figure 1. Changes in liver function tests asociated with prescription of etanercept. 


\section{REFERENCES}

1. Farah M, Al Rashidi A, Owen DA, Yoshida EM, Reid GD. Granulomatous hepatitis associated with etanercept therapy. J Rheumatol 2008;35:349-51.

2. Antoni C, Krueger GG, de Vlam K, et al. Infliximab improves signs and symptoms of psoriatic arthritis: results of the IMPACT 2 Trial. Ann Rheum Dis 2005;64:1150-7.

3. Feletar M, Brockbank JE, Schentag CT, Lapp V, Gladman DD. Treatment of refractory psoriatic arthritis with infliximab: a 12 month observational study of 16 patients. Ann Rheum Dis 2004;63:156-61.

4. Braun J, Brant J, Listing J, et al. Long-term efficacy and safety of infliximab in the treatment of ankylosing spondylitis. An open, observational, extension study of a three-month, randomized placebo-controlled trial. Arthritis Rheum 2003;48:2224-33.

5. Van der Heijde D, Dijkmans B, Geusens P, et al. Efficacy and safety of infliximab in patients with ankylosing spondylitis. Results of a randomized, placebo-controlled trial (ASSERT). Arthritis Rheum 2005;52:582-91.

6. NICE Technology Appraisal Guidance 104: Etanercept and infliximab for the treatment of adults with psoriatic arthritis. London: National Institute for Health and Clinical Excellence; July 2006.

7. Mease PJ, Kivitz AJ, Burch FX, et al. Continued inhibition of radiographic progression in patients with psoriatic arthritis following 2 years of treatment with etanercept. J Rheumatol 2006;33:712-21.

J Rheumatol 2008;35:11; doi:10.3899/jrheum.080521

\section{Deep Venous Thrombosis in Dermatomyositis}

\section{To the Editor:}

Recent reports suggest a marked increase in incidence of venous thromboembolism (deep vein thrombosis, DVT) in patients with Wegener's granulomatosis ${ }^{1}$, a finding that has not been explained by common risk factors for thrombophilia ${ }^{2}$. To our knowledge, an increased incidence of DVT in patients with idiopathic inflammatory myopathy (IIM) has not previously been reported. We describe our experience with a small cohort of patients with IIM.

On review of our hospital electronic medical record (with approval from the institutional review board), 54 patients with a diagnosis of IIM were identified from January 1999 to December 2007. IIM was diagnosed based upon Bohan and Peter criteria ${ }^{3}$ or the Sontheimer definition ${ }^{4}$ for amyopathic dermatomyositis (DM). Six of these patients had been diagnosed with IIM prior to January 1999 but were identified on record review because of continued followup. Of these 54 patients, the following were excluded: 6 patients because of malignancy diagnosed within 3 years of diagnosis of IIM, 2 because of use of warfarin for atrial fibrillation, 1 because of prior instrumentation at the site of venous thrombosis, and 2 patients because of a history of DVT. Of the remaining 43 patients, polymyositis (PM) was diagnosed in 19 and $\mathrm{DM}$ in 24,5 of whom had amyopathic DM.

The median followup of those with IIM was 3 years (range 0.1-26 yrs) with a total followup of 219 person-years. New DVT was diagnosed in 5 patients, all of whom had DM. Hence the incidence of new DVT was about $20 \%$ in DM and about $11 \%$ for IIM as a whole. The incidence rate of DVT in DM was 4.64 per 100 person-years and 2.68 per 100 person-years for IIM. The difference in incidence of DVT between PM and DM was statistically significant ( $p=0.04$, Fisher exact test). In 3 of the 5 patients with new DVT, venous thrombosis was diagnosed within a year of onset of IIM; in 1 it was diagnosed during a disease flare and in 1 it was diagnosed 25 years after onset of IIM. In 2 patients an obvious cause for DVT was not identified, in 1 it was attributed to use of oral contraceptive pills, in 1 it was attributed to a combination of a heterozygous prothrombin gene mutation and a long airplane flight 1 week prior to diagnosis of DVT, and 1 patient reported trauma to the affected extremity 1 week prior to onset of symptoms, which were later diagnosed to be related to DVT. However, detailed investigations for evaluation of a hypercoagulable state were not done in all patients. No patient was treated with intravenous immunoglobulin for IIM.

In a population cohort established to assess cardiovascular risk, the incidence of DVT in the age group 45 to 64 years was $1.22 \%$ over a followup of about 9 years, with an incidence of 0.12 per 100 person-years for first $\mathrm{DVT}^{5}$. When compared to other inflammatory diseases, the incidence of DVT was $1 \%$ in rheumatoid arthritis (incidence 0.26 per 100 person-years $)^{1}, 6 \%$ in lupus $(0.7 \text { per } 100 \text { person-years })^{6}$, and about $10 \%$ in Wegener's granulomatosis (7.0 per 100 person-years) ${ }^{1}$. In our study, the incidence of DVT was $20 \%$ in DM (4.64 per 100 personyears). It is possible that patients with myopathy have reduced mobility secondary to weakness that predisposes them to DVT. However, the occurrence of DVT exclusively in DM, rather than PM, is intriguing. $\mathrm{DM}$ is characterized by perivascular localization of inflammation with microvessel involvement and capillary loss ${ }^{7}$. It is possible that the presence of small-vessel involvement in DM is responsible for the high incidence of DVT, similar to that seen in Wegener's granulomatosis. However, due to the retrospective design of our study in a small cohort, systematic evaluation of all patients for presence of DVT was not done, nor were other risk factors like mobility and hypercoagulable states fully investigated.

We observed an increased incidence of DVT in patients with DM associated with active disease. Further studies at multiple centers would be needed to confirm this, and to elucidate the pathogenesis of thrombosis in these patients.

SHILPA D. GAITONDE, MD, Fellow; STANLEY P. BALLOU, MD, Director, Division of Rheumatology, Metrohealth Campus, Case Western Reserve University, 2500 Metrohealth Drive, Cleveland, Ohio 44109 USA. Address reprint requests to Dr. Gaitonde;

E-mail: sgaitonde@metrohealth.org

\section{REFERENCES}

1. Merkel PA, Lo GH, Holbrook JT, et al; Wegener's Granulomatosis Etanercept Trial Research Group. Brief communication: high incidence of venous thrombotic events among patients with Wegener granulomatosis: the Wegener's Clinical Occurrence of Thrombosis (WeCLOT) Study. Ann Intern Med 2005;142:620-6.

2. Sebastian JK, Voetsch B, Stone JH, et al; Wegener's Granulomatosis Etanercept Trial Research Group. The frequency of anticardiolipin antibodies and genetic mutations associated with hypercoagulability among patients with Wegener's granulomatosis with and without history of a thrombotic event. J Rheumatol 2007;34:2446-50

3. Bohan A, Peter JB. Polymyositis and dermatomyositis (first of two parts). N Engl J Med 1975;292:344-7.

4. Sontheimer RD. Cutaneous features of classic dermatomyositis and amyopathic dermatomyositis. Curr Opin Rheumatol 1999; 11:475-82

5. Cushman M, Tsai AW, White RH, et al. Deep vein thrombosis and pulmonary embolism in two cohorts: the longitudinal investigation of thromboembolism etiology. Am J Med 2004;117:19-25.

6. Sarabi ZS, Chang E, Bobba R, et al. Incidence rates of arterial and venous thrombosis after diagnosis of systemic lupus erythematosus. Arthritis Rheum 2005;53:609-12.

7. Grundtman C, Malmström V, Lundberg IE. Immune mechanisms in the pathogenesis of idiopathic inflammatory myopathies. Arthritis Res Ther 2007;9:208.

J Rheumatol 2008;35:11; doi:10.3899/jrheum.080478 


\section{Respiratory Muscle Weakness with Dermatomyositis During Pregnancy: Successful Treatment with Intravenous Immunoglobulin Therapy}

To the Editor:

Autoimmune myositis is relatively rare in women of reproductive age and very few cases of pregnancy in women with autoimmune myositis have been reported. We describe severe dermatomyositis (DM) that developed during pregnancy, showed an unsatisfactory response to corticosteroid, and required intravenous immunoglobulin (IVIG) therapy.

A 31-year-old woman who was 18 weeks pregnant complained of fever, muscle weakness, erythema, and arthralgia in May 2007. She visited a local clinic, where high serum creatinine kinase (CK) concentration was noted in June 2007, and she was referred to our hospital. On admission, she was 23 weeks pregnant and her fetus had developed normally. A physical examination showed periungual erythema and Gottron's papule on all fingers, and poorly demarcated erythema on both elbows and knees. Symmetrical proximal muscle weakness was found in her upper and lower extremities; the manual muscle testing score was $3 / 5$ for the proximal and distal muscles. She had no family history of muscular disorders. Initial laboratory tests showed the following: CK 6252 IU/1 (normal 37-164), aspartate aminotransferase $289 \mathrm{IU} / \mathrm{l}(7-40)$, alanine transferase $134 \mathrm{IU} / 1(<35)$, lactate dehydrogenase 848 IU/1 (100-225), and aldolase 42.2 U/1 (2.1-6.1). She was positive for antinuclear antibodies (1/160 with a speckled pattern), whereas assays for autoantibodies including anti-Jo-1 were negative.

According to these findings, she was diagnosed as having DM. Prednisolone (PSL) was administered orally at $60 \mathrm{mg} / \mathrm{day}$, with an improvement of the serological markers (CK 1029 IU/1). Although the CK level did not decrease to less than 1000 IU/1 for 4 weeks, PSL was gradually tapered to $35 \mathrm{mg} /$ day in order to avoid steroid myopathy and delay wound healing after a cesarean resection. Fetal growth was monitored by echography and a Doppler scan of uterine arteries once a week by a gynecologist. Fetal growth showed intrauterine growth retardation.

When she was 35 weeks pregnant, on 22 August, she threatened to have a premature delivery. When lumbar anesthesia was performed for cesarean section, she became unconscious due to $\mathrm{CO}_{2}$ narcosis, but delivered an immature healthy baby (1502 g weight) under intratracheal intubation. However, extubation was difficult because of $\mathrm{CO}_{2}$ narcosis due to respiratory muscle weakness. She was treated with IVIG at a dose of $20 \mathrm{~g} / \mathrm{day}$ for 5 consecutive days from 22 August, with steroid therapy (PSL $30 \mathrm{mg} / \mathrm{day}$ ), and serum CK level decreased to 345 IU/1 on 27 August, but respiratory muscle weakness did not normalize. The CK level decreased further to 205 IU/l after 2 weeks and the skin lesions disappeared, while a tracheotomy was performed for $\mathrm{CO}_{2}$ narcosis.

In September, laboratory and clinical examinations showed normalization of muscle enzyme levels and dramatic improvement of muscle strength; the manual muscle testing score was $5 / 5$ for the proximal and distal muscles. After rehabilitation of respiratory muscles, level of $\mathrm{PaCO}_{2}$ decreased gradually with improvement $\left(\mathrm{pH} 7.389, \mathrm{PaO}_{2} 99.3\right.$ torr, and $\mathrm{PaCO}_{2} 48.2$ torr), and she was extubated in October. Then steroids were gradually tapered. She was discharged in good clinical condition.

Pregnancy in association with an autoimmune myositis is a rare event, and this has been attributed to the low percentage of cases $(14 \%)$ in which the disease begins during the reproductive period of a woman's life ${ }^{1}$. In active autoimmune myositis associated with pregnancy, healthy infants resulted in only $30 \%$ and fetal death or abortion in $40 \%$ of cases, whereas during inactive or improved autoimmune myositis, the figures were $57 \%$ and $21.5 \%$, respectively ${ }^{2}$.

Our patient was initially treated with PSL because administration of PSL during pregnancy is considered to be relatively safe for both mother and fetus. Placental enzymes inactivate prednisolone, and hence decrease the steroid concentration in the fetal blood to $10 \%{ }^{3}$. However, her symptoms progressed and CK did not decrease to less than $1000 \mathrm{U} / 1$ in spite of a medium dose of PSL. Treatment options include high-dose PSL and corticosteroid-sparing agents such as methotrexate, azathioprine, mycopheno- late mofetil, cyclosporine, and cyclophosphamide ${ }^{4}$; however, many of these pose infection risk and teratogenic risk to the fetus.

In contrast, IVIG has been administered safely during pregnancy to patients with Guillain-Barre syndrome, antiphospholipid antibody syndrome, myasthenia gravis crisis, idiopathic thrombocytopenic purpura, and similar conditions ${ }^{5}$. The mechanism of the beneficial effects of IVIG in autoimmune myositis is not precisely known but is thought to be related to modulation of pathogenic autoantibodies, suppression of pathogenic cytokines and $\mathrm{Fc}$ receptor blockade, and alteration in $\mathrm{T}$ cell function ${ }^{6}$.

To our knowledge this is the first reported case of $\mathrm{DM}$ with $\mathrm{CO}_{2}$ narcosis due to respiratory muscle weakness during pregnancy, in which treatment with IVIG after delivery resulted in remission of DM. In view of the rarity of pregnancy in active autoimmune myositis, we suggest consideration of IVIG therapy as a possible therapeutic option, given its steroid-sparing effect and the reduced risk of steroid-related side effects.

\section{YUJI NOZAKI, MD; SHINYA IKOMA, MD; MASANORI FUNAUCHI,} MD; KOJI KINOSHITA, MD, Department of Nephrology and Rheumatology, Kinki University School of Medicine, 377-2 OhnoHigashi, Osaka-Sayama, Osaka, 589-8511, Japan. Address reprint requests to Dr. Kinoshita; E-mail: kkino@med.kindai.ac.jp

\section{REFERENCES}

1. Pinheiro G da R, Goldenberg J, Atra E, Pereira RB, Camano L, Schmidt B. Juvenile dermatomyositis and pregnancy: report and literature review. J Rheumatol 1992;19:1798-801.

2. Ishii N, Ono H, Kawaguchi T, Nakajima H. Dermatomyositis and pregnancy. Case report and review of the literature. Dermatologica 1991;183:146-9.

3. Levitz M, Jansen V, Dancis J. The transfer and metabolism of corticosteroids in the perfused human placenta. Am J Obstet Gynecol 1978;132:363-6.

4. Cherin P. Recognition and management of myositis. Drugs 1997;54:39-49.

5. Clark AL. Clinical uses of intravenous immunoglobulin in pregnancy. Clin Obstet Gynecol 1999;42:368-80.

6. Dalakas MC. Intravenous immunoglobulin in the treatment of autoimmune neuromuscular diseases: present status and practical therapeutic guidelines. Muscle Nerve 1999;22:1479-97.

J Rheumatol 2008;35:11; doi:10.3899/jrheum.080389

\section{Parotid Irrigation and Cevimeline Gargle for Treatment of Xerostomia in Sjögren's Syndrome}

\section{To the Editor:}

Xerostomia may be associated with a wide range of diseases including autoimmune diseases such as Sjögren's syndrome (SS) ${ }^{1}$. Cholinergic agents such as pilocarpine and cevimeline have been recently applied to relieve xerostomia in patients with SS. However, adverse effects such as abdominal pain, nausea, diarrhea, and ocular symptoms were major shortcomings in the use of the drugs ${ }^{2,3}$.

Corticosteroid irrigation of the affected salivary glands has been successfully applied to patients with $\mathrm{SS}^{4}$. Further, a preliminary study showed that cevimeline gargle was effective in treating some patients with severe SS who were refractory to treatment with corticosteroid irrigation ${ }^{5}$. In addition, no severe adverse effects were observed with corticosteroid irrigation or cevimeline gargle. These results prompted us to evaluate parotid irrigation and cevimeline gargle for relieving xerostomia in patients with and without SS.

Two hundred seventeen xerostomia patients with $(n=118)$ or without $(n=99)$ SS were treated by parotid gland irrigation with either steroid (patients with $\mathrm{SS} ; 2 \mathrm{mg} / \mathrm{ml}$ prednisolone solution in saline) or saline (patients without SS), followed by the irrigation treatment plus cevimeline 
A

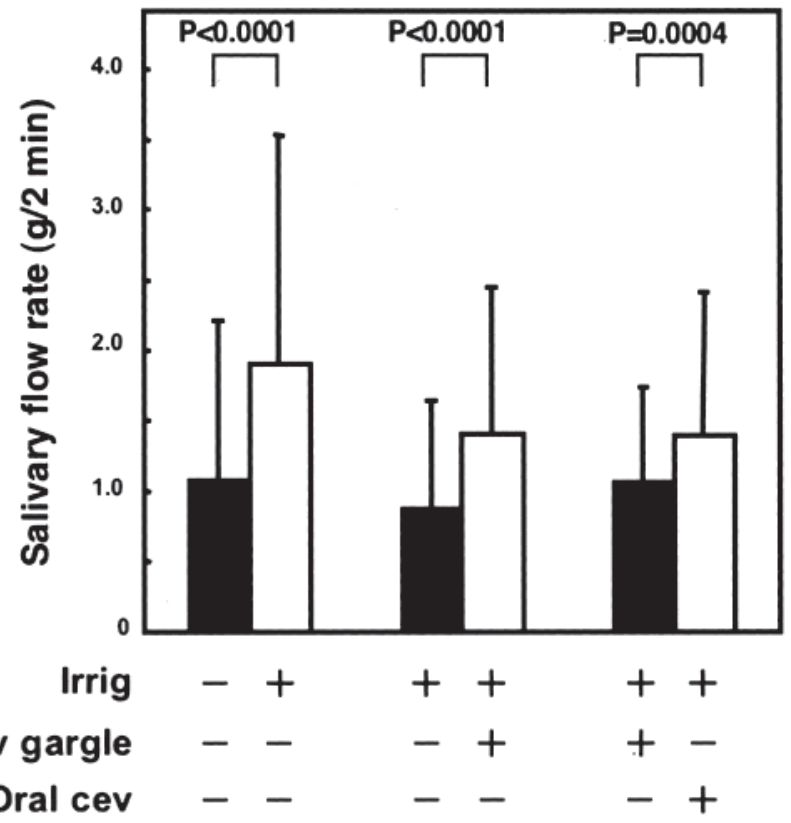

$\mathrm{B}$
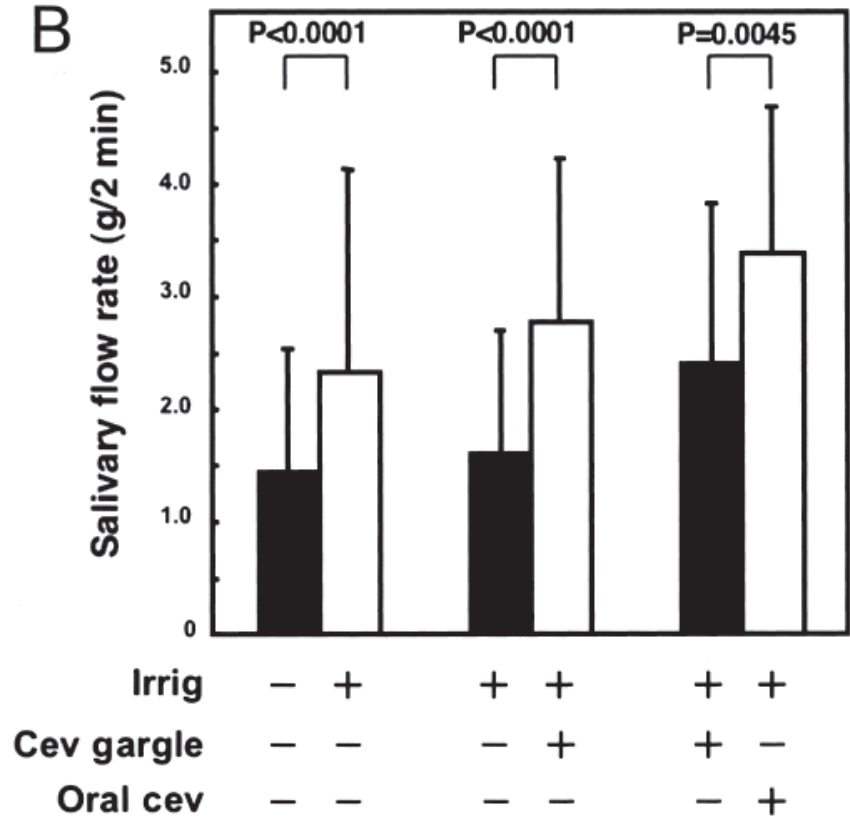

Figure 1. Salivary flow rates after different treatments in patients with and without SS. A. Salivary flow rates in patients with SS who received corticosteroid irrigation (Irrig), corticosteroid irrigation and cevimeline gargle ( $\mathrm{Cev}$ gargle), or corticosteroid irrigation and oral doses of cevimeline (Oral Cev). Each set of bars indicates salivary flow rates (Saxon test) at start (black bar) and end (white bar) of each treatment term. B. Salivary flow rates in patients without SS who received saline irrigation (Irrig), saline irrigation and cevimeline gargle (Cev gargle), or saline irrigation and oral doses of cevimeline (Oral Cev). Each set of bars indicates salivary flow rates at start (black bar) and end (white bar) of each treatment term. Data are expressed as means \pm SD.

gargle (3 times daily, each using $30 \mathrm{mg}$ cevimeline dissolved in $100 \mathrm{ml}$ water) or plus cevimeline gargle and oral cevimeline (30 mg, 1-3 times daily, depending on the patients' tolerance). In the patients with SS, we performed irrigation with saline ( 2 times at an interval of $2 \mathrm{wks}$ ) followed by corticosteroid irrigation (4 times at an interval of $1 \mathrm{wk}$ ). In the patients without SS, saline irrigation was performed at an interval of 2 weeks throughout the course of treatment. The efficacy of each treatment protocol was evaluated by Saxon test, which was performed by one of the authors blinded to the underlying treatment. The patients with SS were categorized into 3 groups (mild, moderate, and severe) based on the magnetic reso- nance imaging features of the parotid gland as described ${ }^{6}$. Approval for our study was obtained from the institutional ethics board at our hospital, and informed consent was obtained from the patients.

Salivary flow rates of the 118 patients with SS who received corticosteroid irrigation alone were significantly higher $(1.90 \pm 1.62 \mathrm{~g} / 2 \mathrm{~min})$ than their pretreatment flow rates $(1.07 \pm 1.13 \mathrm{~g} / 2 \mathrm{~min}$; Figure 1A). Salivary flow rates of patients with SS treated with the corticosteroid irrigation plus cevimeline gargle were significantly higher $(1.41 \pm 1.03 \mathrm{~g} / 2 \mathrm{~min})$ than those treated with the irrigation alone $(0.87 \pm 0.76 \mathrm{~g} / 2 \mathrm{~min})$. In addition, 52 patients with SS who were previously treated with corticosteroid irrigation

Table 1. Treatment efficacy for different protocols in xerostomia patients with Sjögren's syndrome

\begin{tabular}{llccc}
\hline Treatment Groups & Severity* & $\mathrm{n}$ & $\begin{array}{c}\text { Net Increase**, } \\
\mathrm{g} / 2 \min (\%)\end{array}$ & $\begin{array}{c}\text { Length of Treatment } \\
\text { Benefit*** } \\
\text { Average } \pm \text { SD (mo) }\end{array}$ \\
\hline Irrigation & Mild & 29 & & \\
& Moderate & 75 & $1.75 \pm 1.38(332)$ & $11 \pm 2$ \\
& Severe & 7 & $2.07 \pm 1.53(304)$ & $9 \pm 2$ \\
Irrigation and gargle & Mild & 37 & $0.47 \pm 0.57(\mathbf{3 2})$ & $6 \pm 1$ \\
& Moderate & 15 & $1.66 \pm 1.03(288)$ & $8 \pm 2$ \\
Irrigation and oral dose & Severe & 11 & $1.51 \pm 1.05(326)$ & $9 \pm 2$ \\
& Mild & 52 & $0.28 \pm 0.64(\mathbf{1 4 4})$ & $5 \pm 1$ \\
& Moderate & 9 & $1.34 \pm 1.18(198)$ & $7 \pm 2$ \\
Total & Severe & 27 & $1.01 \pm 0.62(97)$ & $7 \pm 2$ \\
& & 118 & $0.43 \pm 0.31(\mathbf{2 2 4})$ & $5 \pm 2$ \\
& & & \\
\end{tabular}

* Severity of parotid gland disease was elevated based on the MRI criteria ${ }^{6}$ ** Significance of difference in treatment efficacy among the different treatment protocols was tested by Kruskal-Wallis rank test (bold type $=$ significantly different, $\mathrm{p}=0.0253$ ). *** Length of treatment benefit based on Saxon test results ${ }^{4}$. Irrigation: corticosteroid irrigation; gargle: cevimeline gargle; Oral dose: oral dose of cevimeline. 
plus cevimeline gargle $(1.06 \pm 0.67 \mathrm{~g} / 2 \mathrm{~min})$ showed further increase in salivary flow rates when treated with oral doses of cevimeline plus irrigation $(1.39 \pm 1.02 \mathrm{~g} / 2 \mathrm{~min})$.

There was no significant difference in treatment efficacy among the 3 protocols in the SS patients with mildly or moderately affected glands (Table 1). However, in the SS patients with severely affected glands, the treatment with irrigation plus cevimeline gargle was more effective than irrigation treatment alone, and oral doses of cevimeline were more effective than cevimeline gargle. In addition, the irrigation treatment significantly improved the salivary flow rates of the patients with and without SS treated with cevimeline gargle alone (data not shown). The length of treatment benefit was dependent on the severity of the disease (Table 1).

The saline irrigation was effective in patients without SS $(1.43 \pm 1.09$ vs $2.32 \pm 1.79 \mathrm{~g} / 2 \mathrm{~min}$; Figure $1 \mathrm{~B})$. The cevimeline gargle exerted additive effects on the salivary flow rates of the non-SS patients treated with saline irrigation alone $(1.59 \pm 1.08$ vs $2.77 \pm 1.44 \mathrm{~g} / 2 \mathrm{~min})$. Treatment with oral doses of cevimeline improved the flow rate even further $(2.40 \pm 1.40 \mathrm{vs}$ $3.38 \pm 1.28 \mathrm{~g} / 2 \mathrm{~min})$.

Adverse effects associated with oral doses of cevimeline occurred more frequently in the patients with SS than in those without, suggesting increased sensitivity to the drug in the patients with SS. Adverse effects also occurred with the cevimeline gargle; however, the incidence was much lower than with oral doses of cevimeline. In contrast, irrigation treatment with corticosteroid or saline was not associated with any adverse effects.

Our study confirmed earlier results regarding the usefulness of corticosteroid irrigation for patients with $\mathrm{SS}^{5}$ and further showed that (1) irrigation therapy with the saline solution significantly relieved xerostomia in patients without SS; (2) cevimeline gargle treatment could be an effective adjunct to irrigation therapy for xerostomia in patients with and without SS; and (3) oral doses of cevimeline improved salivary flow rates of xerostomia patients with or without SS. The major beneficial effects were observed in SS patients with severe disease and oral-dose cevimeline. We found no evidence in the blood for cevimeline absorption through the mucosa after the gargle. Instead, the cevimeline might directly activate the minor salivary gland acini.

YUKINORI TAKAGI, DDS, PhD; IKUO KATAYAMA, DDS, PhD; SHIGEKI TASHIRO, PhD; TAKASHI NAKAMURA, DDS, PhD, Professor and Chief, Department of Radiology and Cancer Biology, Nagasaki University School of Dentistry, 1-7-1 Sakamoto, Nagasaki, 852-8588, Japan.

Address reprint requests to Dr. Nakamura. E-mail: taku@nagasaki-u.ac.jp

\section{REFERENCES}

1. Mavragani CP, Moutsopoulos NM, Moutosopoulos HM. The management of Sjögren's syndrome. Nat Clin Pract Rheumatol 2006;2:252-61.

2. Petrone D, Condemi JJ, Fife R, Gluck O, Cohen S, Dalgin P. A double-blind, randomized, placebo-controlled study of cevimeline in Sjögren's syndrome patients with xerostomia and keratoconjunctivitis sicca. Arthritis Rheum 2002;46:748-54.

3. Fife RS, Chase WF, Dore RK, et al. Cevimeline for the treatment of xerostomia in patients with Sjögren syndrome: a randomized trial. Arch Intern Med 2002;162:1239-300.

4. Izumi M, Eguchi K, Nakamura H, Takagi Y, Kawabe Y, Nakamura T. Corticosteroid irrigation of parotid gland for treatment of xerostomia in patients with Sjögren's syndrome. Ann Rheum Dis 1998;57:464-9.

5. Takagi Y, Kimura Y, Nakamura T. Cevimeline gargle for the treatment of xerostomia in patients with Sjögren's syndrome. Ann Rheum Dis 2004;63:749.

6. Takagi Y, Sumi M, Sumi T, Ichikawa Y, Nakamura T. MR microscopy of the parotid glands in patients with Sjögren's syndrome: quantitative MR diagnostic criteria. AJNR Am J Neuroradiol 2005;26:1207-14.

J Rheumatol 2008;35:11; doi:10.3899/jrheum.080370
Recurrent Intestinal Perforation Associated with Thrombosis of Inferior Vena Cava: Uncommon Presentation of Antiphospholipid Syndrome

\section{To the Editor:}

Antiphospholipid syndrome (APS) is characterized by a state of hypercoagulability potentially resulting in thrombosis of all segments of the vascular bed ${ }^{1,2}$, fetal loss, and moderate thrombocytopenia ${ }^{3,4}$. APS is associated with elevated titers of antiphospholipid antibodies (aPL) and/or lupus anticoagulant (LAC) $)^{5,6}$. Gastrointestinal manifestations are rarely observed (about $1.5 \%$ of patients) and intestinal infarction, resulting from mesenteric vessel thrombosis, has been infrequently reported ${ }^{3}$. The presentation may be acute (acute abdomen), often preceded by intestinal angina ${ }^{1}$. Rarely, thrombosis of large vessels (aorta and inferior vena cava) has also been reported in association with $\mathrm{aPL}^{7}$. We describe a case of recurrent intestinal perforation and thrombosis of the inferior vena cava occurring as APS presentation.

A 33-year-old man developed an acute abdomen treated with laparoscopic appendicectomy in February 2006. In March 2006 he was admitted again to the local hospital for a second episode of acute abdomen. Abdominal computed tomography (CT) scan demonstrated the presence of ascites, and emergency laparotomy was performed. Small bowel perforation was found and was treated by segmental resection. Abdominal pain and fever $\left(38^{\circ} \mathrm{C}\right)$ persisted after surgical treatment and a further abdominal CT scan confirmed the suspicion of another intestinal perforation. A second laparotomy was performed and $20 \mathrm{~cm}$ of jejunum were resected. Histological examination of operative specimens showed intestinal mucosal necrosis with perforation, congestion, and infiltration of lymphocytes, plasmacytes and multinucleated giant cells. The diagnosis of chronic inflammatory bowel disease, such as Crohn's disease, was made and treatment with oral budesonide ileal-release capsules (9 mg once a day) and 5aminosalicylic acid (ASA; Pentasa, $4 \mathrm{~g}$ once a day) was started.

Unfortunately, abdominal pain and intermittent fever $\left(38^{\circ}-38.5^{\circ} \mathrm{C}\right)$ were always present and in June 2006 the patient was admitted again to the local hospital for another acute abdomen. Emergency laparotomy demonstrated an ileal perforation and a further segmental resection was performed. Treatment with oral budesonide and 5-ASA was continued. Nevertheless, he reported progressive worsening of the abdominal pain, and sometimes fever, anorexia, nausea, vomiting, and weight loss. In December 2007 he presented another acute abdomen and emergency laparotomy demonstrated a further small bowel perforation, which was resected as well. Budesonide was stopped and oral prednisone $(50 \mathrm{mg}$ once a day) was started.

He was admitted to our department in February 2008 for the onset of right abdominal pain and melena. Abdominal CT scan demonstrated a right-colon covered perforation and partial thrombosis of the inferior vena cava. Celiac and superior and inferior mesenteric artery angiographic studies proved the abnormal origin and course of the splenic artery from the abdominal aorta, of the hepatic artery from the superior mesenteric artery, and of the left gastric artery from the splenic artery, but excluded arteritis and/or arterial thrombosis. Antinuclear antibodies, antineutrophil cytoplasmic antibodies, and anti-Saccharomyces cerevisiae antibodies of $\mathrm{IgG}$ and IgA class were negative. At that time, results of the search for aPL showed elevated titers of IgM anticardiolipin (> $120 \mathrm{UPL} / \mathrm{ml}$ ) and antiphosphatidylserine $(>120 \mathrm{RU} / \mathrm{ml})$ antibodies, but not anti $-\beta_{2}$-glycoprotein I antibodies. The aPL positivity was confirmed in May 2008. LAC activity and serological tests for syphilis were negative. Serum levels of protein C, protein $\mathrm{S}$, and antithrombin III were in the normal range. The search for HLA-B27 and HLA-B51 antigens was also negative. Moreover, our patient was a heterozygous carrier of methylenetetrahydrofolate reductase (MTHFR) C677T gene mutation, but factor V Leiden and prothrombin G20210A gene mutations were absent. Plasma homocysteine level was in the normal range. Finally, the histological reexamination of jejunum operative specimens confirmed intestinal mucosal necrosis with perforation, congestion, and infiltration of lymphocytes, plasmacytes and multinucleat- 
ed giant cells, suggestive of an inflammatory granulomatous foreign-body reaction to a point of suture, and also showed intestinal small-vessel thrombosis without signs of vasculitis.

Therefore, the previous diagnosis of Crohn's disease was questioned. Clinical, immunological, and imaging data were suggestive for the diagnosis of recurrent intestinal perforations in association with partial thrombosis of the inferior vena cava as presentation of primary APS. Total parenteral nutrition was administered and treatment with low-dose aspirin (100 mg/day), low molecular-weight heparin (4000 IU twice a day), and oral warfarin was started. After 10 days of total parenteral nutrition, abdominal CT scan demonstrated remission of the right-colon covered perforation, but not of the partial thrombosis of the inferior vena cava. Total parenteral nutrition was stopped. Finally, aspirin and low molecular-weight heparin were stopped when international normalized ratio reached a value between 2 and 3. At present, the patient feels well and is treated with oral warfarin.

Elevated levels of aPL are associated with increased risk of venous and arterial thrombosis ${ }^{5,8}$. APS was first defined as a triad of thrombosis, fetal loss, and thrombocytopenia, but the definition soon evolved into that of a systemic condition that may be even more systemic than lupus ${ }^{6}$. According to the recently revised Sapporo criteria, APS is diagnosed if at least one of the clinical criteria and one of the laboratory criteria are met ${ }^{9}$. In our patient, the diagnosis of APS was made on the basis of the presence of recurrent intestinal perforation and partial thrombosis of the inferior vena cava associated with elevated aPL levels. Intestinal infarction due to thrombosis of mesenteric vessels has been infrequently reported in patients with $\mathrm{aPL}^{1}$ and, to our knowledge, only 1 case of recurrent intestinal perforations as a presentation of APS has been reported ${ }^{10}$. Our patient did not present superior mesenteric, inferior mesenteric, and celiac artery thrombosis, but intestinal small-vessel thrombosis and partial thrombosis of the inferior vena cava. Large and small-vessel thrombosis are considered the cause of multiple organ ischemia and dysfunction, including gastrointestinal involvement, in patients with APS ${ }^{1,11-13}$. Finally, our patient was a heterozygous carrier of MTHFR C677T gene mutation with normal plasma homocysteine level; these are not associated with risk of venous thrombo$\operatorname{sis}^{14-16}$.

We hypothesize that our patient had recurrent intestinal perforations that were not initially diagnosed as intestinal manifestations of APS. Therefore, we propose that any abdominal disease of uncertain diagnosis should be considered as a suspicious manifestation of APS, and accurate histological examination and/or reexamination of intestinal biopsy or operative specimens should be made to assess the presence of thrombotic microangiopathy. Finally, as the true incidence of intestinal involvement in APS is probably underestimated, screening for aPL should be carried out in patients who present unexplained signs of intestinal angina.

GIUSEPPE MURDACA, MD, PhD; PAOLA CAGNATI, MD; ROSSELLA GULLI, PhD; MATTEO CAITI, MD, Department of Internal Medicine; FRANCESCO BOCCARDO, MD; CORRADINO CAMPISI, MD, Department of Surgery; FRANCESCO PUPPO, MD, Department of Internal Medicine, Viale Benedetto XV, 6, 16132 Genova, Italy. Address reprint requests to Prof. Murdaca.

\section{REFERENCES}

1. Uthman I, Khamashta M. The abdominal manifestations of the antiphospholipid syndrome. Rheumatology Oxford 2007;46:1641-7.

2. Khamashta MA, Bertolaccini ML, Hughes GR. Antiphospholipid (Hughes) syndrome. Autoimmunity 2004;37:309-12.

3. Bachmeyer C, Barrier A, Frazier A, et al. Diffuse large and small bowel necrosis in catastrophic antiphospholipid syndrome. Eur J Gastroenterol Hepatol 2006;18:1011-4.

4. Levine JS, Branch DW, Rauch J. The antiphospholipid syndrome. N Engl J Med 2002;346:752-63.

5. Hughes GR. Hughes syndrome (the antiphospholipid syndrome): ten clinical lessons. Autoimmun Rev 2008;7:262-6.

6. Shoenfeld Y, Meroni PL, Cervera R. Antiphospholipid syndrome dilemmas still to be solved: 2008 status. Ann Rheum Dis 2008;67:438-42.

7. Di Centa I, Fadel E, Mussot S, et al. Occlusion of the aorta and inferior vena cava in a patient with circulating anticoagulants. Ann Vasc Surg 2002;16:380-3.

8. Aichbichler BW, Petritsch W, Reicht GA, et al. Anti-cardiolipin antibodies in patients with inflammatory bowel disease. Dig Dis Sci 1999;44:852-6.

9. Miyakis S, Lockshin MD, Atsumi T, et al. International consensus statement on an update of the classification criteria for definite antiphospholipid syndrome (APS). J Thromb Haemost 2006;4:295-306.

10. Al-Daqal S, Mansouri M, Qari MH, Sibiany A. Recurrent intestinal perforations as a presentation of antiphospholipid syndrome. Ann Saudi Med 2006;26:52-5.

11. Cervera R, Espinosa G, Corsero A, et al. Intestinal involvement secondary to the antiphospholipid syndrome (APS): clinical and immunologic characteristics of 97 patients: comparison of classic and catastrophic APS. Semin Arthritis Rheum 2007;36:287-96.

12. Asherson RA, Cervera R. Microvascular and microangiopathic antiphospholipid-associated syndromes ("MAPS"): semantic or antisemantic? Autoimmun Rev 2008;7:164-7.

13. Kaushik S, Federle MP, Schur PH, et al. Abdominal thrombotic and ischemic manifestations of the antiphospholipid antibody syndrome: CT findings in 42 patients. Radiology 2001;218:768-71.

14. Bezemer ID, Doggen CJ, Vos HL, Rosendaal FR. No association between the common MTHFR 677C->T polymorphism and venous thrombosis: results from the MEGA study. Arch Intern Med 2007; 167:497-501.

15. Kutteh WH, Park VM, Deitcher SR. Hypercoagulable state mutation analysis in white patients with early first-trimester recurrent pregnancy loss. Fertil Steril 1999;71:1048-53.

16. Ray JG. Meta-analysis of hyperhomocysteinemia as a risk factor for venous thromboembolic disease. Arch Intern Med 1998;158:2101-6.

J Rheumatol 2008;35:11; doi:10.3899/jrheum.080585

\section{Back Pain in a Patient with Wegener's Granulomatosis}

\section{To the Editor:}

Wegener's granulomatosis (WG) is a rare, systemic, necrotizing granulomatous inflammation with vasculitis, usually affecting the upper and lower respiratory tracts and kidneys ${ }^{1,2}$. WG is commonly associated with nonspecific systemic signs such as fever, weight loss, arthralgia, and myalgia. Although most patients initially present with upper airway illness, articular involvement with, typically, arthritis is frequent during the clinical course ${ }^{3}$. Vertebral involvement is rare and is mainly due to granulomatous tissue in the dural space that can lead to neurologic symptoms ${ }^{4-6}$.

We describe a patient with WG whose main complaint was severe back pain due to a large thoracic prevertebral mass without dural involvement.

A 55-year-old-man was admitted to our rheumatology department with fever, weakness, weight loss and severe inflammatory thoracic back pain. He had a history of rhinitis, sinusitis, and epistaxis a few months previous1y. Clinical examination was normal. Routine laboratory studies revealed increased erythrocyte sedimentation rate $(109 \mathrm{~mm} / \mathrm{h})$ and C-reactive protein (CRP; $149 \mathrm{mg} / \mathrm{l})$. White blood cell (WBC) count was $17,400 / \mathrm{mm}^{3}$, with 11,390 neutrophils and 990 eosinophils. Renal function was initially normal and urinalysis did not reveal an abnormal level of protein. Chest and thoracolumbar spine radiographs were normal. Thoracic computed tomography (CT) revealed a prevertebral mass extending from T4 to T10 and a right pleural effusion. Thoracic magnetic resonance imaging (MRI) 


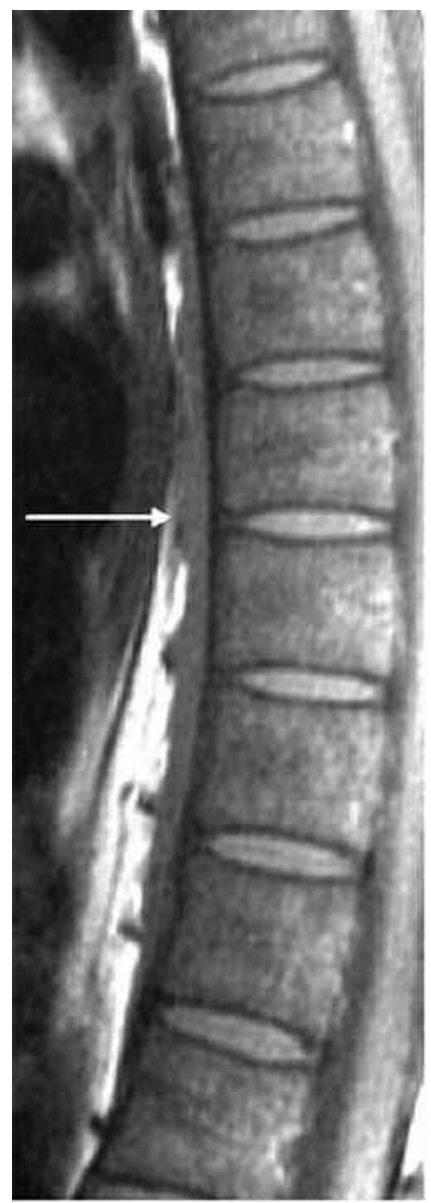

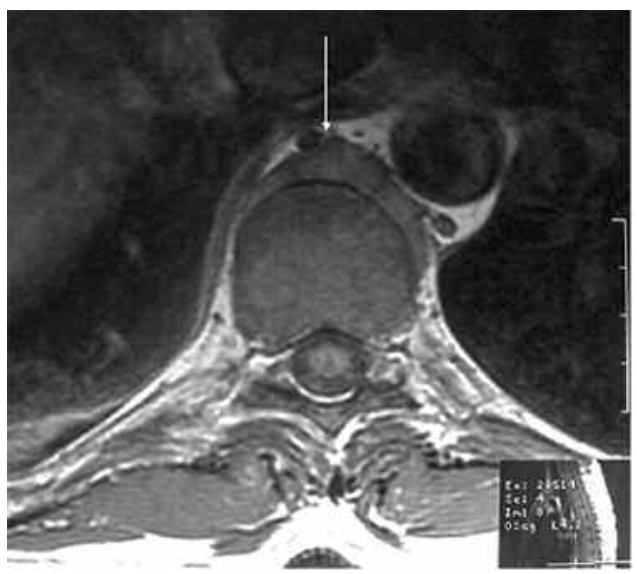

Figure 2. Axial T1-weighted spin-echo MRI of well defined soft-tissue mass in the prevertebral space.

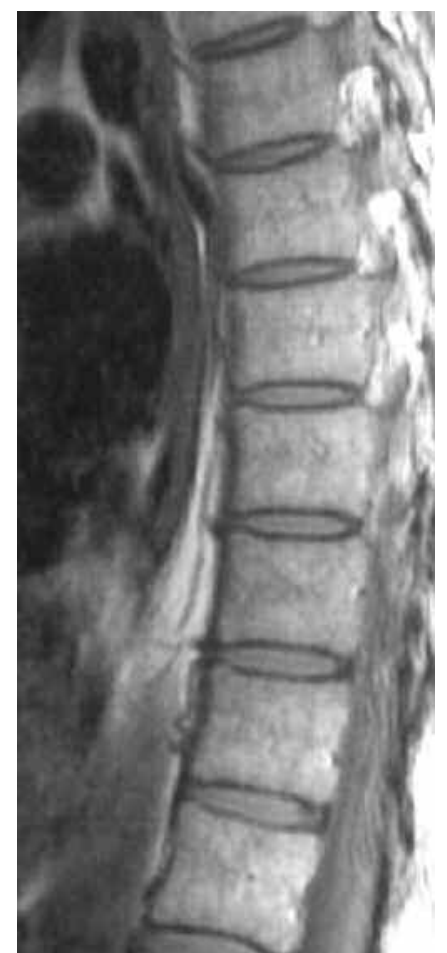

Figure 3. Sagittal T1-weighted spinecho MRI shows total regression of the prevertebral soft-tissue mass following immunosuppressive treatments.

Figure 1. Sagittal T1-weighted spin-echo MRI of thin pre-

vertebral soft-tissue mass extending from $\mathrm{T} 4$ to $\mathrm{T} 10$.

revealed prevertebral soft-tissue thickening with homogenous enhancement extending from T4 to T10. Enhancement was also present in the anterior part of the vertebral body close to the prevertebral mass. This soft-tissue mass was minimally hypointense on T1-weighted magnetic resonance imaging (MRI) and prominently hyperintense on contrast-enhanced T1weighted MRI (Figures 1 and 2). The vertebral discs and dural space showed no signal abnormality. Testing for rheumatoid factor, antinuclear antibodies, and anti-DNA antibodies was negative. Testing for perinuclear antineutrophil cytoplasmic antibody (p-ANCA) was positive by indirect immunofluorescence (1/200) and directed against myeloperoxidase on ELISA $(120 \mathrm{U} / \mathrm{ml})$.

During hospitalization, his serum creatinine concentration increased rapidly, to $230 \mu \mathrm{mol} / \mathrm{l}$, which was accompanied by proteinuria $(1 \mathrm{~g} / 24 \mathrm{~h})$ and hematuria $\left(200 \mathrm{red}\right.$ blood cells $/ \mathrm{mm}^{3}$ ). A needle biopsy of the kidney disclosed necrotic and crescentic glomerulonephritis. Immunofluorescence staining revealed no immune deposits. On the basis of these histologic findings, the presence of p-ANCA, and past upper airway symptoms suggestive of granuloma disease, a diagnosis of WG was established according to a described algorithm ${ }^{7}$. Treatment with monthly courses of intravenous cyclophosphamide (CYC) and oral corticosteroids ( $1 \mathrm{mg} / \mathrm{kg}$ daily) was initiated. After 6 courses of CYC, serum CRP decreased to within the normal range, and serum p-ANCA diminished sharply. Fever disappeared and the thoracic pain gradually decreased. Therapy with CYC was switched to azathioprine $100 \mathrm{mg}$ daily for 8 months, and corticosteroid therapy was slowly tapered. A control vertebral MRI 1 year after the initiation of treatment revealed total regression of the prevertebral soft-tissue mass (Figure 3). After 2 years, the thoracic pain had totally disappeared, as had the inflammatory syndrome, and results for p-ANCA remained negative, so prednisone was stopped. At the last followup visit, 3 years later, the patient was free of symptoms and had normal laboratory test results, except for mild persistant renal insufficiency (creatinine $120 \mu \mathrm{mol} / \mathrm{l}$ ).

WG is included with ANCA-associated small-vessel vasculitis. Peripheral musculoskeletal involvement occurs in about two-thirds of patients with WG. Although most patients experience only arthralgia or myalgia, monoarthritis or polyarthritis may occur. Vertebral involvement is very rare. In most cases, spinal manifestations are related to extradural and subdural granulomatous involvement of spinal meninges ${ }^{5}$. Cardenal, et al recently reported a case very similar to ours, a patient showing p-ANCA positivity with thoracic back pain related to a fusiform prevertebral soft-tissue mass extending from $\mathrm{T} 8$ to $\mathrm{T} 10^{8}$. We hypothesize that the prevertebral soft-tissue mass in both patients contained granulomatous tissue, because the mass disappeared following immunosuppressive treatment.

Although in most cases the diagnosis of WG is quite straightforward, WG may have unusual presentation ${ }^{9}$. Our case highlights the variety of symptoms that may present as the initial clinical manifestation of WG. Thickening of the ligaments and masses caused by WG need to be distinguished from other diseases, including abscesses or tumors. In most cases, the distinction between WG and tumors can be made on the basis of associated clinical, immunological, or radiologic findings. However, in cases with an uncommon location, as in our patient, WG and tumors can be distinguished only histologically. In our case, rapid renal failure led to a renal biopsy that revealed crescentic glomerulonephritis, which develops in 50\% to $70 \%$ of patients with $\mathrm{WG}^{1}$.

CYC combined with high-dose corticosteroids is recommended as induction treatment in WG. Once remission is obtained, azathioprine is widely used as maintenance therapy ${ }^{10}$. This therapeutic plan allowed for total disappearance of the prevertebral mass and longterm remission in our patient. 
Thoracic back pain may be the main complaint in patients with WG. This unusual presentation must be added to the list of presenting symptoms of WG, because early specific treatment is essential for a favorable outcome.

SAMAR KERKENI, MD; THOMAS BARDIN, MD; PASCAL RICHETTE MD, PhD, Université Paris 7, UFR médicale, Assistance Publique-Hôpitaux de Paris, Hôpital Lariboisière, Fédération de Rhumatologie, 2 Rue Ambroise Paré, 75475 Paris Cedex 10, France. Address reprint requests to Dr. P. Richette; E-mail: pascal.richette@lrb.aphp.fr

\section{REFERENCES}

1. Jennette JC, Falk RJ. Small-vessel vasculitis. N Engl J Med 1997;337:1512-23.

2. Mahr AD, Neogi T, Merkel PA. Epidemiology of Wegener's granulomatosis: Lessons from descriptive studies and analyses of genetic and environmental risk determinants. Clin Exp Rheumatol 2006;24:S82-91.

3. Puechal X. Antineutrophil cytoplasmic antibody-associated vasculitides. Joint Bone Spine 2007;74:427-35.

4. Bachmeyer C, Cervera P, Marro B, et al. Thoracic spinal cord compression indicating Wegener's granulomatosis in a patient with a previous presumptive diagnosis of microscopic polyangiitis. Joint Bone Spine 2007;74:382-4.
5. Albayram S, Kizilkilie O, Adaletli I, Erdogan N, Kocer N, Islak C. MR imaging findings of spinal dural involvement with Wegener granulomatosis. AJNR Am J Neuroradiol 2002;23:1603-6.

6. Wang DC, Wei JW, Liu JH, Hu YG. The upper thoracic spinal cord compression as the initial manifestation of Wegener's granulomatosis: a case report. Eur Spine J 2007;16 Suppl 3:296-300.

7. Watts R, Lane S, Hanslik T, et al. Development and validation of a consensus methodology for the classification of the ANCA-associated vasculitides and polyarteritis nodosa for epidemiological studies. Ann Rheum Dis 2007;66:222-7.

8. Cardenal-Urdampilleta J, Gorospe L, Marquez C, Segur V, Romera B. Wegener's granulomatosis mimicking a thoracic spondylodiscitis. J Rheumatol 2007;34:1779-81.

9. Vandergheynst F, Van Gansbeke D, Cogan E. Wegener's granulomatosis masquerading as a renal cancer: a case report and review of the literature. Clin Exp Rheumatol 2006;24:584-6.

10. Bosch X, Guilabert A, Espinosa G, Mirapeix E. Treatment of antineutrophil cytoplasmic antibody associated vasculitis: a systematic review. JAMA 2007;298:655-69.

J Rheumatol 2008;35:11; doi:10.3899/jrheum.080396 